Supplement of Biogeosciences, 12, 5161-5184, 2015

http://www.biogeosciences.net/12/5161/2015/

doi:10.5194/bg-12-5161-2015-supplement

(C) Author(s) 2015. CC Attribution 3.0 License.

(c) (i)

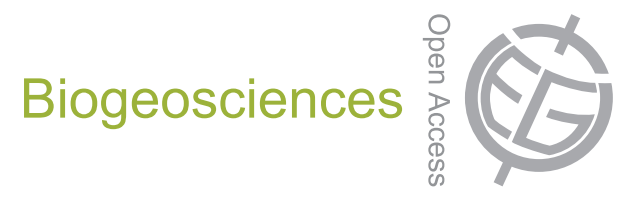

Supplement of

\title{
The greenhouse gas balance of a drained fen peatland is mainly controlled by land-use rather than soil organic carbon content
}

\section{T. Eickenscheidt et al.}

Correspondence to: T. Eickenscheidt (tim.eickenscheidt@hswt.de)

The copyright of individual parts of the supplement might differ from the CC-BY 3.0 licence. 
Table S1 Model parameters of the $\mathrm{A} 1 \mathrm{C}_{\text {medium site. }}$

\begin{tabular}{|c|c|c|c|c|c|c|c|c|c|c|c|c|c|c|c|c|c|c|c|c|c|c|c|c|c|}
\hline \multirow[b]{3}{*}{ Site } & \multirow[b]{3}{*}{ Date } & \multicolumn{10}{|l|}{$R_{\mathrm{ECO} O}$} & \multicolumn{9}{|l|}{ GPP } & \multicolumn{5}{|c|}{$R_{E \subset C O}$ without model parameter } \\
\hline & & \multirow[b]{2}{*}{$R_{e f t}$} & \multirow[b]{2}{*}{$E_{0}$} & \multicolumn{2}{|c|}{ Std. Error } & \multicolumn{4}{|c|}{$95 \%$ Confidence Limits } & \multirow[b]{2}{*}{$n$} & \multirow[b]{2}{*}{ model based on } & \multirow[b]{2}{*}{$\alpha$} & \multicolumn{3}{|c|}{ Std. Error } & \multicolumn{4}{|c|}{ 95\% Confidence Limits } & \multirow[b]{2}{*}{$n$} & \multirow{2}{*}{$\begin{array}{l}\text { daily mean } \\
R_{\in \in o}[\mu m o l \\
\left.\mathrm{CO}_{2} \mathrm{~m}^{-2} \mathrm{~s}^{-1}\right] \\
\end{array}$} & \multirow{2}{*}{$\begin{array}{l}\text { Std. Error } \\
R_{E \subset O}\end{array}$} & \multicolumn{3}{|c|}{$95 \%$ Contidence Limits } \\
\hline & & & & $R_{e f t}$ & $E_{0}$ & lower $R_{\text {ret }}$ & upper $R_{\text {ret }}$ & lower $E_{0}$ & upper $E_{0}$ & & & & $G P P_{2000}$ & $\alpha$ & $G P P_{2000}$ & lower $\alpha$ & upper $a$ & $\begin{array}{l}\text { lower } \\
G P P_{2000}\end{array}$ & $\begin{array}{l}\text { upper } \\
G P P_{2000}\end{array}$ & & & & lower $R_{\mathrm{E} c 0}$ & upper $R_{\in c o}$ & $n$ \\
\hline $\mathrm{A} 1 \mathrm{C}_{\text {medium }}$ & 2010-02-09 & - & - & - & - & - & - & - & - & - & - & - & - & - & - & - & - & - & - & - & 0.78 & 0.18 & 0.44 & 1.11 & 9 \\
\hline $\mathrm{A} 1 \mathrm{C}_{\text {medium }}$ & 2010-02-25 & - & - & - & - & - & - & - & - & - & - & -0.01 & -6.91 & 0.00 & 0.15 & -0.01 & -0.01 & -7.22 & -6.61 & 36 & 0.92 & 0.12 & 0.69 & 1.15 & 15 \\
\hline $\mathrm{A} 1 \mathrm{C}_{\text {medium }}$ & 2010-03-08 & - & - & - & - & - & - & - & - & - & - & - & - & - & - & - & - & - & - & - & 1.11 & 0.09 & 0.95 & 1.28 & 9 \\
\hline $\mathrm{A} 1 \mathrm{C}_{\text {medium }}$ & 2010-03-24 & 3.43 & 138.31 & 0.06 & 7.64 & 3.32 & 3.55 & 122.73 & 153.89 & 33 & $T_{\text {air }}$ & -0.01 & -10.44 & 0.00 & 0.25 & -0.01 & -0.01 & -10.94 & -9.93 & 55 & - & - & - & - & - \\
\hline $\mathrm{A} 1 \mathrm{C}_{\text {medium }}$ & 2010-04-07 & 7.99 & 119.04 & 0.26 & 19.17 & 7.43 & 8.55 & 78.41 & 159.67 & 18 & $S T_{2}$ & -0.02 & -21.89 & 0.00 & 0.73 & -0.02 & -0.01 & -23.37 & -20.42 & 44 & - & - & - & - & - \\
\hline $\mathrm{A} 1 \mathrm{C}_{\text {medium }}$ & $2010-04-28$ & 9.62 & 103.31 & 0.40 & 17.69 & 8.77 & 10.47 & 65.60 & 141.02 & 17 & $S T_{2}$ & -0.03 & -28.78 & 0.00 & 1.00 & -0.03 & -0.02 & -30.84 & -26.73 & 26 & - & - & - & - & - \\
\hline $\mathrm{A} 1 \mathrm{C}_{\text {medium }}$ & $2010-05-23$ & 6.73 & 231.96 & 0.71 & 35.92 & 5.27 & 8.19 & 157.65 & 306.26 & 25 & $S T_{2}$ & - & - & - & - & - & - & - & - & - & - & - & - & - & - \\
\hline $\mathrm{A} 1 \mathrm{C}_{\text {medium }}$ & 2010-06-10 & - & - & - & - & - & - & - & - & - & - & -0.01 & -11.00 & 0.00 & 0.54 & -0.01 & -0.01 & -12.11 & -9.89 & 27 & 9.15 & 0.27 & 8.63 & 9.67 & 17 \\
\hline $\mathrm{A} 1 \mathrm{C}_{\text {medium }}$ & 2010-07-02 & 12.59 & 110.77 & 1.24 & 23.54 & 10.02 & 15.16 & 61.82 & 159.72 & 23 & $T_{\text {air }}$ & -0.03 & -29.42 & 0.01 & 1.78 & -0.04 & -0.02 & -33.03 & -25.81 & 36 & - & - & - & - & - \\
\hline $\mathrm{A} 1 \mathrm{C}_{\text {medium }}$ & $2010-07-22$ & 11.34 & 218.93 & 0.64 & 23.03 & 10.03 & 12.65 & 171.89 & 265.97 & 32 & $T_{\text {air }}$ & -0.06 & -67.47 & 0.01 & 1.68 & -0.07 & -0.05 & -70.94 & -64.01 & 27 & - & - & - & - & - \\
\hline $\mathrm{A} 1 \mathrm{C}_{\text {medium }}$ & 2010-08-21 & 7.43 & 143.40 & 0.54 & 16.74 & 6.28 & 8.58 & 107.90 & 178.89 & 18 & $T_{\text {air }}$ & -0.04 & -42.18 & 0.01 & 1.27 & -0.05 & -0.03 & -44.83 & -39.53 & 22 & - & - & - & - & - \\
\hline $\mathrm{A} 1 \mathrm{C}_{\text {medium }}$ & 2010-09-12 & 6.28 & 135.16 & 0.48 & 21.87 & 5.25 & 7.31 & 88.27 & 182.06 & 16 & $T_{\text {air }}$ & -0.01 & -33.80 & 0.00 & 1.92 & -0.02 & -0.01 & -37.80 & -29.80 & 22 & - & - & - & - & - \\
\hline $\mathrm{A} 1 \mathrm{C}_{\text {medium }}$ & 2010-10-04 & 4.62 & 202.38 & 0.18 & 14.43 & 4.23 & 5.01 & 171.21 & 233.55 & 15 & $T_{\text {air }}$ & -0.05 & -20.85 & 0.01 & 1.44 & -0.07 & -0.02 & -23.98 & -17.72 & 14 & - & - & - & - & - \\
\hline $\mathrm{A} 1 \mathrm{C}_{\text {medium }}$ & $2010-10-13$ & 6.10 & 175.57 & 0.54 & 46.50 & 4.83 & 7.37 & 65.62 & 285.52 & 9 & $T_{\text {air }}$ & -0.01 & -13.33 & 0.00 & 7.28 & -0.02 & 0.00 & -32.05 & 5.39 & 7 & - & - & - & - & - \\
\hline $\mathrm{A} 1 \mathrm{C}_{\text {medium }}$ & 2010-10-29 & 4.70 & 104.79 & 0.36 & 36.38 & 3.93 & 5.47 & 26.77 & 182.81 & 16 & $T_{\text {air }}$ & -0.01 & -18.61 & 0.00 & 4.97 & -0.01 & 0.00 & -29.14 & -8.08 & 18 & - & - & - & - & - \\
\hline $\mathrm{A} 1 \mathrm{C}_{\text {medium }}$ & $2010-12-13$ & - & - & - & - & - & - & - & - & - & - & - & - & - & - & - & - & - & - & - & 0.20 & 0.06 & 0.09 & 0.31 & 9 \\
\hline $\mathrm{A} 1 \mathrm{C}_{\text {medium }}$ & 2011-01-05 & - & - & - & - & - & - & - & - & - & - & - & - & - & - & - & - & - & - & - & 0.82 & 0.14 & 0.56 & 1.09 & 9 \\
\hline A1C $C_{\text {medium }}$ & 2011-01-27 & - & - & - & - & - & - & - & - & - & - & - & - & - & - & - & - & - & - & - & 0.75 & 0.02 & 0.72 & 0.79 & 9 \\
\hline $\mathrm{A} 1 \mathrm{C}_{\text {medium }}$ & 2011-02-07 & 1.28 & 151.19 & 0.09 & 41.66 & 1.09 & 1.48 & 61.20 & 241.19 & 15 & $T_{\text {air }}$ & - & - & - & - & - & - & - & - & - & - & - & - & - & - \\
\hline $\mathrm{A} 1 \mathrm{C}_{\text {medium }}$ & 2011-03-08 & 1.07 & 32.45 & 0.04 & 10.60 & 0.99 & 1.15 & 10.09 & 54.81 & 19 & $T_{\text {air }}$ & - & - & - & - & - & - & - & - & - & - & - & - & - & - \\
\hline $\mathrm{A} 1 \mathrm{C}_{\text {medium }}$ & 2011-03-29 & 4.16 & 196.91 & 0.18 & 25.69 & 3.78 & 4.53 & 142.93 & 250.89 & 20 & $T_{\text {air }}$ & -0.01 & -14.78 & 0.00 & 1.31 & -0.01 & 0.00 & -17.53 & -12.04 & 22 & - & - & - & - & - \\
\hline $\mathrm{A} 1 \mathrm{C}_{\text {medium }}$ & 2011-04-20 & - & - & - & - & - & - & - & - & - & - & - & - & - & - & - & - & - & - & - & 8.92 & 0.19 & 7.91 & 9.94 & 23 \\
\hline $\mathrm{A} 1 \mathrm{C}_{\text {medium }}$ & 2011-05-06 & 5.90 & 79.18 & 0.24 & 15.44 & 5.39 & 6.41 & 47.06 & 111.29 & 23 & $T_{\text {air }}$ & -0.01 & -8.27 & 0.00 & 0.55 & -0.02 & -0.01 & -9.39 & -7.15 & 36 & - & - & - & - & - \\
\hline $\mathrm{A} 1 \mathrm{C}_{\text {medium }}$ & $2011-05-25$ & 14.57 & 76.98 & 1.02 & 19.05 & 12.41 & 16.72 & 36.59 & 117.36 & 18 & $S T_{2}$ & -0.03 & -34.06 & 0.01 & 1.44 & -0.04 & -0.02 & -36.99 & -31.12 & 32 & - & - & - & - & - \\
\hline $\mathrm{A} 1 \mathrm{C}_{\text {medium }}$ & 2011-06-28 & 14.88 & 124.68 & 1.12 & 19.41 & 12.56 & 17.20 & 84.43 & 164.93 & 24 & $T_{\text {air }}$ & -0.16 & -52.10 & 0.02 & 0.84 & -0.20 & -0.12 & -53.81 & -50.39 & 30 & - & - & - & - & - \\
\hline $\mathrm{A} 1 \mathrm{C}_{\text {medium }}$ & 2011-08-02 & 10.82 & 133.18 & 0.67 & 18.45 & 9.41 & 12.23 & 94.26 & 172.10 & 19 & $T_{\text {air }}$ & -0.15 & -29.02 & 0.03 & 0.79 & -0.21 & -0.08 & -30.64 & -27.40 & 30 & - & - & - & - & - \\
\hline $\mathrm{A} 1 \mathrm{C}_{\text {medium }}$ & $2011-08-24$ & - & - & - & - & - & - & - & - & - & - & - & - & - & - & - & - & - & - & - & 14.22 & 0.20 & 13.32 & 15.11 & 19 \\
\hline $\mathrm{A} 1 \mathrm{C}_{\text {medium }}$ & 2011-09-24 & 7.30 & 177.34 & 0.30 & 20.51 & 6.66 & 7.94 & 133.64 & 221.05 & 17 & $T_{\text {air }}$ & -0.02 & -28.26 & 0.00 & 2.35 & -0.03 & -0.02 & -33.25 & -23.28 & 18 & - & - & - & - & - \\
\hline $\mathrm{A} 1 \mathrm{C}_{\text {medium }}$ & 2011-10-16 & 9.69 & 207.95 & 0.37 & 22.25 & 8.90 & 10.49 & 160.52 & 255.38 & 17 & $S T_{2}$ & -0.03 & -33.29 & 0.00 & 1.48 & -0.03 & -0.02 & -36.37 & -30.20 & 23 & - & - & - & - & - \\
\hline $\mathrm{A} 1 \mathrm{C}_{\text {medium }}$ & 2011-12-15 & 2.42 & 168.70 & 0.20 & 31.97 & 1.95 & 2.89 & 93.11 & 244.28 & 9 & $T_{\text {air }}$ & -0.04 & -16.40 & 0.00 & 3.16 & -0.05 & -0.03 & -24.13 & -8.66 & 8 & - & - & - & - & - \\
\hline$A 1 C_{\text {medium }}$ & 2012-01-12 & 4.53 & 302.37 & 0.55 & 59.54 & 3.28 & 5.78 & 167.69 & 437.06 & 11 & $T_{\text {air }}$ & -0.02 & -21.94 & 0.01 & 7.93 & -0.03 & -0.01 & -39.21 & -4.66 & 14 & - & - & - & - & - \\
\hline
\end{tabular}


Table S2 Model parameters of the A1 $\mathrm{C}_{\text {high }}$ site.

\begin{tabular}{|c|c|c|c|c|c|c|c|c|c|c|c|c|c|c|c|c|c|c|c|c|c|c|c|c|c|}
\hline \multirow[b]{3}{*}{ Site } & \multirow[b]{3}{*}{ Date } & \multicolumn{10}{|l|}{$R_{\in \in O O}$} & \multicolumn{9}{|l|}{ GPP } & \multicolumn{5}{|l|}{$R_{E \in c}$ without model } \\
\hline & & \multirow[b]{2}{*}{$R_{\text {ret }}$} & \multirow[b]{2}{*}{$E_{0}$} & \multicolumn{2}{|c|}{ Std. Error } & \multicolumn{4}{|c|}{ 95\% Confidence Limits } & \multirow[b]{2}{*}{$n$} & \multirow[b]{2}{*}{$\begin{array}{c}\text { model } \\
\text { based on }\end{array}$} & \multirow[b]{2}{*}{$a$} & \multirow[b]{2}{*}{$G P P_{2000}$} & \multicolumn{2}{|c|}{ Std. Error } & \multicolumn{4}{|c|}{ 95\% Confidence Limits } & \multirow[b]{2}{*}{$n$} & \multirow[b]{2}{*}{$\begin{array}{l}\text { daily mean } R_{\mathrm{Eco}} \\
{\left[\mu \mathrm{mol} \mathrm{CO}_{2} \mathrm{~m}^{-2} \mathrm{~s}^{-1}\right\rfloor}\end{array}$} & \multirow{2}{*}{$\begin{array}{l}\text { Std. Error } \\
R_{\in \subset \subset O}\end{array}$} & \multirow{2}{*}{\multicolumn{2}{|c|}{$\begin{array}{l}95 \% \text { Confidence Limits } \\
\text { lower } R_{E \in O} \quad \text { upper } R_{E \in C O}\end{array}$}} & \\
\hline & & & & $R_{\text {ef }}$ & $E_{0}$ & lower $R_{\text {eft }}$ & upper $R_{\text {ift }}$ & lower $E_{0}$ & upper $E_{0}$ & & & & & $a$ & $G P P_{2000}$ & lower $\alpha$ & upper $\alpha$ & $\begin{array}{l}\text { lower } \\
\text { GPP }\end{array}$ & $\begin{array}{l}\text { upper } \\
G P P_{2000}\end{array}$ & & & & & & $n$ \\
\hline A1Chigh & 2010-02-09 & - & - & - & - & - & - & - & - & - & - & - & - & - & - & - & - & - & - & - & 0.30 & 0.14 & 0.05 & 0.56 & 9 \\
\hline A1Chigh & $2010-02-25$ & - & - & - & - & - & - & - & - & - & - & - & - & - & - & - & - & - & - & - & 0.15 & 0.04 & 0.07 & 0.23 & 9 \\
\hline A1Chigh & 2010-03-08 & - & - & - & - & - & - & - & - & - & - & - & - & - & - & - & - & - & - & - & 1.07 & 0.09 & 0.90 & 1.25 & 9 \\
\hline A1 Chigh & 2010-03-24 & 2.49 & 76.95 & 0.07 & 13.88 & 2.34 & 2.64 & 48.53 & 105.38 & 30 & $T_{\text {air }}$ & 0.00 & -2.46 & 0.00 & 0.12 & -0.01 & 0.00 & -2.71 & -2.21 & 44 & - & - & - & - & - \\
\hline A1C $C_{\text {high }}$ & 2010-04-06 & 4.59 & 81.94 & 0.20 & 23.27 & 4.16 & 5.02 & 32.85 & 131.03 & 20 & $T_{\text {air }}$ & 0.00 & -3.57 & 0.00 & 0.18 & -0.01 & 0.00 & -3.94 & -3.19 & 30 & - & - & - & - & - \\
\hline A1 $C_{\text {nigh }}$ & $2010-04-28$ & 5.84 & 155.65 & 0.34 & 33.27 & 5.11 & 6.57 & 84.29 & 227.01 & 16 & $S T_{5}$ & -0.01 & -8.94 & 0.00 & 0.51 & -0.01 & 0.00 & -10.00 & -7.89 & 24 & - & - & - & - & - \\
\hline A1C high & $2010-05-23$ & 2.95 & 106.80 & 0.23 & 27.68 & 2.45 & 3.45 & 47.82 & 165.79 & 17 & $T_{\text {air }}$ & - & - & - & - & - & - & - & - & - & - & - & - & - & - \\
\hline A1 Chigh $_{\text {na }}$ & 2010-06-10 & 1.39 & 404.93 & 0.19 & 36.87 & 0.98 & 1.79 & 327.15 & 482.70 & 19 & $S T_{2}$ & -0.01 & -9.42 & 0.00 & 0.30 & -0.01 & -0.01 & -10.04 & -8.80 & 29 & - & - & - & - & - \\
\hline A1 Chigh & 2010-07-02 & 23.46 & 42.87 & 1.83 & 21.10 & 19.33 & 27.59 & 4.86 & 90.60 & 11 & $T_{\text {air }}$ & -0.02 & -17.50 & 0.01 & 1.43 & -0.03 & 0.00 & -20.50 & -14.50 & 20 & - & - & - & - & - \\
\hline A1 $C_{\text {high }}$ & $2010-07-21$ & 12.61 & 88.94 & 1.14 & 21.86 & 10.20 & 15.02 & 42.83 & 135.05 & 19 & $T_{\text {air }}$ & -0.04 & -37.67 & 0.01 & 1.76 & -0.05 & -0.02 & -41.28 & -34.06 & 30 & - & - & - & - & - \\
\hline A1 $C_{\text {nigh }}$ & $2010-08-21$ & 6.66 & 146.95 & 0.47 & 18.09 & 5.65 & 7.67 & 107.88 & 186.02 & 15 & $T_{\text {air }}$ & -0.04 & -24.30 & 0.01 & 1.27 & -0.05 & -0.02 & -26.99 & -21.60 & 18 & - & - & - & - & - \\
\hline A1C $C_{\text {nigh }}$ & 2010-09-12 & 5.73 & 81.71 & 0.33 & 17.09 & 5.01 & 6.44 & 44.79 & 118.63 & 15 & $T_{\text {air }}$ & -0.01 & -20.57 & 0.00 & 1.09 & -0.02 & -0.01 & -22.80 & -18.34 & 30 & - & - & - & - & - \\
\hline A1C high & 2010-10-04 & 4.54 & 203.09 & 0.39 & 36.90 & 3.67 & 5.40 & 120.88 & 285.29 & 12 & $T_{\text {air }}$ & -0.03 & -20.40 & 0.01 & 1.25 & -0.05 & -0.02 & -23.12 & -17.69 & 14 & - & - & - & - & - \\
\hline A1Chigh & $2010-10-13$ & 14.00 & 577.38 & 2.83 & 138.77 & 7.48 & 20.51 & 257.36 & 897.39 & 10 & $S T_{2}$ & -0.02 & -15.84 & 0.01 & 8.05 & -0.04 & 0.00 & -33.23 & 1.56 & 15 & - & - & - & - & - \\
\hline A1C high & $2010-10-29$ & 2.76 & 87.44 & 0.07 & 12.46 & 2.60 & 2.92 & 60.30 & 114.59 & 14 & $T_{\text {air }}$ & -0.01 & -10.84 & 0.00 & 3.14 & -0.01 & 0.00 & -17.57 & -4.10 & 16 & - & - & - & - & - \\
\hline A1C Chigh & $2010-12-13$ & - & - & - & - & - & - & - & - & - & - & - & - & - & - & - & - & - & - & - & 0.07 & 0.03 & 0.03 & 0.12 & 9 \\
\hline A1Chigh & 2011-01-05 & - & - & - & - & - & - & - & - & - & - & - & - & - & - & - & - & - & - & - & 1.85 & 0.33 & 1.23 & 2.47 & 9 \\
\hline A1 Chigh & $2011-01-27$ & - & - & - & - & - & - & - & - & - & - & - & - & - & - & - & - & - & - & - & 0.47 & 0.06 & 0.42 & 0.52 & 9 \\
\hline A1Chigh & 2011-02-07 & - & - & - & - & - & - & - & - & - & - & - & - & - & - & - & - & - & - & - & 1.20 & 0.09 & 1.03 & 1.37 & 15 \\
\hline A1Chigh & 2011-03-08 & 1.20 & 64.75 & 0.04 & 13.73 & 1.11 & 1.29 & 35.10 & 94.41 & 15 & Tair & - & - & - & - & - & - & - & - & - & - & - & - & - & - \\
\hline A1C nigh & 2011-03-29 & 3.06 & 250.34 & 0.19 & 35.10 & 2.65 & 3.47 & 175.52 & 325.16 & 17 & $T_{\text {air }}$ & -0.01 & -10.48 & 0.00 & 0.46 & -0.01 & -0.01 & -11.45 & -9.51 & 21 & - & - & - & - & - \\
\hline A1 Chigh $_{\text {na }}$ & $2011-04-20$ & - & - & - & - & - & - & - & - & - & - & - & - & - & - & - & - & - & - & - & 2.98 & 0.11 & 2.76 & 3.20 & 24 \\
\hline A1 $C_{\text {high }}$ & $2011-05-06$ & 4.33 & 167.57 & 0.18 & 20.60 & 3.96 & 4.70 & 124.11 & 211.03 & 19 & $S T_{5}$ & -0.01 & -5.85 & 0.00 & 0.27 & -0.01 & 0.00 & -6.39 & -5.31 & 42 & - & - & - & - & - \\
\hline A1C high & $2011-05-25$ & 12.13 & 68.75 & 0.46 & 11.91 & 11.08 & 13.17 & 41.81 & 95.69 & 11 & $T_{\text {air }}$ & -0.08 & -33.08 & 0.01 & 0.71 & -0.10 & -0.06 & -34.53 & -31.62 & 31 & - & - & - & - & - \\
\hline A1 $C_{\text {nigh }}$ & 2011-06-28 & 13.41 & 150.82 & 0.49 & 10.04 & 12.37 & 14.45 & 129.64 & 171.99 & 19 & $T_{\text {air }}$ & -0.10 & -41.08 & 0.01 & 0.82 & -0.12 & -0.07 & -42.80 & -39.37 & 23 & - & - & - & - & - \\
\hline A1Chigh & 2011-08-02 & 6.49 & 96.67 & 0.34 & 13.66 & 5.77 & 7.21 & 67.98 & 125.36 & 20 & $T_{\text {air }}$ & -0.01 & -7.74 & 0.00 & 0.26 & -0.02 & -0.01 & -8.28 & -7.21 & 22 & - & - & - & - & - \\
\hline A1 Chigh & 2011-08-24 & - & - & - & - & - & - & - & - & - & - & - & - & - & - & - & - & - & - & - & 11.69 & 0.10 & 10.86 & 12.52 & 17 \\
\hline A1C high & 2011-09-24 & 4.43 & 137.92 & 0.27 & 28.27 & 3.85 & 5.01 & 77.29 & 198.55 & 16 & $T_{\text {air }}$ & -0.03 & -17.13 & 0.00 & 0.71 & -0.04 & -0.02 & -18.64 & -15.63 & 19 & - & - & - & - & - \\
\hline A1C high & 2011-10-16 & 5.71 & 86.06 & 0.14 & 12.31 & 5.42 & 6.00 & 59.82 & 112.29 & 17 & $T_{\text {air }}$ & -0.01 & -14.30 & 0.00 & 0.89 & -0.02 & -0.01 & -16.16 & -12.43 & 21 & - & - & - & - & - \\
\hline A1Chigh & 2011-12-15 & - & - & - & - & - & - & - & - & - & - & -0.03 & -12.11 & 0.00 & 2.21 & -0.03 & -0.02 & -17.78 & -6.43 & 11 & 0.41 & 0.05 & 0.32 & 0.49 & 9 \\
\hline A1C high & 2012-01-12 & 1.03 & 301.93 & 0.11 & 68.91 & 0.79 & 1.27 & 153.06 & 450.81 & 15 & $T_{\text {air }}$ & -0.01 & -11.43 & 0.00 & 3.50 & -0.01 & 0.00 & -18.86 & -4.01 & 18 & - & - & - & - & - \\
\hline
\end{tabular}


Table S3 Model parameters of the $\mathrm{A}_{2} \mathrm{C}_{\text {medium }}$ site.

\begin{tabular}{|c|c|c|c|c|c|c|c|c|c|c|c|c|c|c|c|c|c|c|c|c|c|c|c|c|c|}
\hline \multirow[b]{3}{*}{ Site } & \multirow[b]{3}{*}{ Date } & \multicolumn{10}{|l|}{$R_{E \subset O}$} & \multicolumn{9}{|l|}{ GPP } & \multicolumn{5}{|l|}{$R_{\varepsilon \in C O}$ without model } \\
\hline & & \multirow[b]{2}{*}{$R_{\text {eft }}$} & \multirow[b]{2}{*}{$E_{0}$} & \multicolumn{2}{|c|}{ Std. Error } & \multicolumn{4}{|c|}{ 95\% Confidence Limits } & \multirow[b]{2}{*}{$n$} & \multirow{2}{*}{$\begin{array}{c}\text { model } \\
\text { based on }\end{array}$} & \multirow[b]{2}{*}{$\alpha$} & \multirow[b]{2}{*}{$G P P_{2000}$} & \multicolumn{2}{|c|}{ Std. Error } & \multicolumn{4}{|c|}{ 95\% Confidence Limits } & \multirow[b]{2}{*}{$n$} & \multirow{2}{*}{ 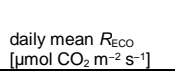 } & \multirow{2}{*}{$\begin{array}{l}\text { Std. Error } \\
R_{E \subset O O}\end{array}$} & \multicolumn{2}{|c|}{ 95\% Confidence Limits } & \\
\hline & & & & $R_{\text {eft }}$ & $E_{0}$ & lower $R_{\text {ref }}$ & upper $R_{\text {ief }}$ & lower $E_{0}$ & upper $E_{0}$ & & & & & $a$ & $G P P_{2000}$ & lower $\alpha$ & upper $\alpha$ & $\begin{array}{l}\text { lower } \\
G P P_{2000}\end{array}$ & $\begin{array}{l}\text { upper } \\
G P P_{2000}\end{array}$ & & & & lower $R_{E \subset O}$ & upper $R_{\mathrm{ECO}}$ & $n$ \\
\hline $\mathrm{A} 2 \mathrm{C}_{\text {mosium }}$ & 2010-02-09 & - & - & - & - & - & - & - & - & - & - & - & - & - & - & - & - & - & - & - & 0.78 & 0.18 & 0.44 & 1.11 & 9 \\
\hline $\mathrm{A} 2 \mathrm{C}_{\text {motium }}$ & 2010-02-25 & - & - & - & - & - & - & - & - & - & - & -0.01 & -6.91 & 0.00 & 0.15 & -0.01 & -0.01 & -7.22 & -6.61 & 36 & 0.92 & 0.12 & 0.69 & 1.15 & 15 \\
\hline $\mathrm{A} 2 \mathrm{C}_{\text {metium }}$ & 2010-03-08 & - & - & - & - & - & - & - & - & - & - & - & - & - & - & - & - & - & - & - & 1.11 & 0.09 & 0.95 & 1.28 & 9 \\
\hline $\mathrm{A}^{2} \mathrm{C}_{\text {motium }}$ & 2010-03-24 & 3.43 & 138.31 & 0.06 & 7.64 & 3.32 & 3.55 & 122.73 & 153.89 & 33 & $T_{\text {air }}$ & -0.01 & -10.44 & 0.00 & 0.25 & -0.01 & -0.01 & -10.94 & -9.93 & 55 & - & - & - & - & - \\
\hline $\mathrm{A}^{\mathrm{A}} \mathrm{C}_{\text {motium }}$ & 2010-04-06 & - & - & - & - & - & - & - & - & - & - & - & - & - & - & - & - & - & - & - & 5.48 & 0.55 & 4.44 & 6.53 & 15 \\
\hline $\mathrm{A} 2 \mathrm{C}_{\text {metium }}$ & 2010-04-07 & - & - & - & - & - & - & - & - & - & - & - & - & - & - & - & - & - & - & - & 4.53 & 0.30 & 3.96 & 5.09 & 19 \\
\hline $\mathrm{A}^{2 \mathrm{C}_{\text {mosum }}}$ & 2010-04-28 & - & - & - & - & - & - & - & - & - & - & - & - & - & - & - & - & - & - & - & 7.68 & 0.33 & 7.04 & 8.32 & 18 \\
\hline $\mathrm{A}^{2 \mathrm{C}_{\text {mosum }}}$ & $2010-05-23$ & 4.94 & 239.51 & 0.27 & 18.32 & 4.39 & 5.49 & 201.62 & 277.40 & 25 & Tair & -0.06 & -24.05 & 0.00 & 0.25 & -0.07 & -0.05 & -24.57 & -23.54 & 38 & - & - & - & - & - \\
\hline $\mathrm{A}^{2} \mathrm{C}_{\text {modum }}$ & $2010-06-10$ & 12.65 & 48.50 & 0.72 & 13.26 & 11.10 & 14.21 & 20.06 & 76.95 & 16 & $T_{\text {air }}$ & -0.08 & -34.35 & 0.02 & 1.44 & -0.12 & -0.04 & -37.31 & -31.38 & 26 & - & - & - & - & - \\
\hline $\mathrm{A}^{2 \mathrm{C}_{\text {mosum }}}$ & 2010-07-02 & 15.39 & 105.33 & 1.14 & 15.77 & 13.00 & 17.78 & 72.21 & 138.45 & 20 & $T_{\text {air }}$ & -0.15 & -47.21 & 0.03 & 1.56 & -0.20 & -0.09 & -50.37 & -44.04 & 36 & - & - & - & - & - \\
\hline $\mathrm{A}^{2 \mathrm{C}_{\text {motum }}}$ & $2010-07-22$ & 13.58 & 328.79 & 2.34 & 71.82 & 8.48 & 18.68 & 172.29 & 485.28 & 14 & $S T_{2}$ & -0.08 & -54.20 & 0.01 & 1.64 & -0.10 & -0.05 & -57.70 & -50.70 & 17 & - & - & - & - & - \\
\hline $\mathrm{A}^{2 \mathrm{C}_{\text {motum }}}$ & $2010-08-21$ & 9.82 & 55.31 & 0.90 & 22.33 & 7.92 & 11.72 & 7.98 & 102.65 & 18 & $T_{\text {air }}$ & -0.02 & -12.72 & 0.00 & 0.40 & -0.03 & -0.01 & -13.57 & -11.87 & 20 & - & - & - & - & - \\
\hline $\mathrm{A}^{2 \mathrm{C}_{\text {motum }}}$ & 2010-09-12 & - & - & - & - & - & - & - & - & - & - & - & - & - & - & - & - & - & - & - & 6.13 & 0.40 & 5.37 & 6.90 & 16 \\
\hline $\mathrm{A}^{2} \mathrm{C}_{\text {modum }}$ & $2010-10-04$ & 3.35 & 114.22 & 0.23 & 26.44 & 2.86 & 3.84 & 56.61 & 171.84 & 14 & $T_{\text {air }}$ & - & - & - & - & - & - & - & - & - & - & - & - & - & - \\
\hline $\mathrm{A}^{2 \mathrm{C}_{\text {metum }}}$ & $2010-10-29$ & 3.51 & 109.14 & 0.10 & 14.11 & 3.29 & 3.72 & 79.07 & 139.21 & 17 & $T_{\text {air }}$ & -0.01 & -9.40 & 0.00 & 1.31 & -0.01 & 0.00 & -12.31 & -6.48 & 12 & - & - & - & - & - \\
\hline $\mathrm{A} 2 \mathrm{C}_{\text {motum }}$ & $2010-12-13$ & - & - & - & - & - & - & - & - & - & - & - & - & - & - & - & - & - & - & - & 0.17 & 0.01 & 0.15 & 0.19 & 9 \\
\hline $\mathrm{A}^{2} \mathrm{C}_{\text {modum }}$ & 2011-01-05 & - & - & - & - & - & - & - & - & - & - & - & - & - & - & - & - & - & - & - & 0.70 & 0.16 & 0.40 & 1.00 & 9 \\
\hline $\mathrm{A}^{2} \mathrm{C}_{\text {motum }}$ & $2011-01-27$ & - & - & - & - & - & - & - & - & - & - & - & - & - & - & - & - & - & - & - & 1.02 & 0.04 & 0.95 & 1.09 & 9 \\
\hline $\mathrm{A}^{2} \mathrm{C}_{\text {motum }}$ & 2011-02-07 & 1.27 & 119.11 & 0.09 & 39.12 & 1.07 & 1.47 & 34.59 & 203.63 & 15 & $T_{\text {air }}$ & 0.00 & -1.50 & 0.00 & 0.67 & 0.00 & 0.00 & -2.87 & -0.13 & 34 & - & - & - & - & - \\
\hline $\mathrm{A} 2 \mathrm{C}_{\text {motum }}$ & 2011-03-08 & 1.63 & 110.71 & 0.05 & 13.91 & 1.34 & 1.75 & 47.28 & 163.19 & 19 & $T_{\text {air }}$ & - & - & - & - & - & - & - & - & - & - & - & - & - & - \\
\hline $\mathrm{A}^{2} \mathrm{C}_{\text {medum }}$ & 2011-03-29 & 4.30 & 237.53 & 0.17 & 24.85 & 3.94 & 4.66 & 185.33 & 289.74 & 20 & $T_{\text {air }}$ & -0.01 & -15.21 & 0.00 & 1.28 & -0.01 & -0.01 & -17.85 & -12.57 & 26 & - & - & - & - & - \\
\hline $\mathrm{A}^{2 \mathrm{C}_{\text {mosum }}}$ & $2011-04-20$ & 17.78 & 81.14 & 2.43 & 44.53 & 12.71 & 22.84 & -11.75 & 174.02 & 22 & $T_{\text {air }}$ & - & - & - & - & - & - & - & - & - & - & - & - & - & - \\
\hline $\mathrm{A} 2 \mathrm{C}_{\text {medum }}$ & 2011-05-06 & - & - & - & - & - & - & - & - & - & - & - & - & - & - & - & - & - & - & - & 3.39 & 0.07 & 3.08 & 3.70 & 23 \\
\hline $\mathrm{A}^{2 \mathrm{C}_{\text {mosum }}}$ & 2011-05-25 & - & - & - & - & - & - & - & - & - & - & - & - & - & - & - & - & - & - & - & 6.06 & 0.15 & 5.70 & 6.41 & 22 \\
\hline $\mathrm{A}^{2} \mathrm{C}_{\text {metum }}$ & $2011-06-28$ & 9.05 & 151.48 & 0.74 & 20.79 & 7.51 & 10.58 & 108.36 & 194.59 & 24 & $T_{\text {air }}$ & -0.06 & -50.00 & 0.01 & 1.61 & -0.08 & -0.04 & -53.29 & -46.71 & 30 & - & - & - & - & - \\
\hline $\mathrm{A}^{2 \mathrm{C}_{\text {mosum }}}$ & $2011-08-02$ & 9.67 & 215.74 & 1.08 & 31.17 & 7.40 & 11.93 & 150.50 & 280.99 & 21 & $T_{\text {air }}$ & -0.14 & -79.49 & 0.03 & 3.32 & -0.21 & -0.07 & -86.28 & -72.69 & 30 & - & - & - & - & - \\
\hline $\mathrm{A} 2 \mathrm{C}_{\text {motum }}$ & $2011-08-24$ & 15.56 & 116.88 & 1.89 & 30.61 & 11.58 & 19.55 & 52.29 & 181.46 & 19 & $T_{\text {air }}$ & -0.12 & -85.43 & 0.02 & 4.04 & -0.17 & -0.08 & -93.67 & -77.19 & 33 & - & - & - & - & - \\
\hline $\mathrm{A}^{2} \mathrm{C}_{\text {modum }}$ & $2011-09-24$ & 4.95 & 218.83 & 0.18 & 17.84 & 4.56 & 5.33 & 180.82 & 256.85 & 17 & $T_{\text {air }}$ & -0.01 & -26.59 & 0.00 & 3.01 & -0.02 & -0.01 & -32.89 & -20.30 & 21 & - & - & - & - & - \\
\hline $\mathrm{A} 2 \mathrm{C}_{\text {motum }}$ & $2011-10-16$ & 2.65 & 136.11 & 0.05 & 14.55 & 2.54 & 2.76 & 105.41 & 166.81 & 19 & $T_{\text {air }}$ & -0.01 & -7.35 & 0.00 & 0.80 & -0.02 & 0.00 & -9.02 & -5.68 & 23 & - & - & - & - & - \\
\hline $\mathrm{A} 2 \mathrm{C}_{\text {mosum }}$ & 2011-12-15 & 1.91 & 202.88 & 0.18 & 39.64 & 1.47 & 2.35 & 109.14 & 296.62 & 9 & Tair & -0.01 & -4.35 & 0.00 & 1.50 & -0.02 & -0.01 & -8.02 & -0.68 & 8 & - & - & - & - & - \\
\hline $\mathrm{A} 2 \mathrm{C}_{\text {modium }}$ & 2012-01-12 & 2.35 & 256.47 & 0.22 & 44.32 & 1.84 & 2.85 & 156.21 & 356.73 & 11 & $T_{\text {air }}$ & -0.01 & -6.71 & 0.00 & 0.47 & -0.01 & -0.01 & -7.75 & -5.68 & 14 & - & - & - & - & - \\
\hline
\end{tabular}


Table S4 Model parameters of the $\mathrm{A} \mathrm{C}_{\text {high }}$ site.

\begin{tabular}{|c|c|c|c|c|c|c|c|c|c|c|c|c|c|c|c|c|c|c|c|c|c|c|c|c|c|}
\hline \multirow[b]{3}{*}{ Site } & \multirow[b]{3}{*}{ Date } & \multicolumn{10}{|l|}{$R_{\mathrm{ECO}}$} & \multicolumn{9}{|l|}{ GPP } & \multicolumn{5}{|l|}{$R_{E \in O}$ without model } \\
\hline & & \multirow[b]{2}{*}{$R_{\text {eft }}$} & \multirow[b]{2}{*}{$E_{0}$} & \multicolumn{2}{|c|}{ Std. Error } & \multicolumn{4}{|c|}{ 95\% Confidence Limits } & \multirow[b]{2}{*}{$n$} & \multirow{2}{*}{$\begin{array}{c}\text { model } \\
\text { based on }\end{array}$} & \multirow[b]{2}{*}{$a$} & \multirow[b]{2}{*}{$G P P_{2000}$} & \multicolumn{2}{|c|}{ Std. Error } & \multicolumn{4}{|c|}{ 95\% Confidence Limits } & \multirow[b]{2}{*}{$n$} & \multirow{2}{*}{$\begin{array}{l}\text { daily mean } R_{E \mathrm{co}} \\
{\left[\mu \mathrm{mol} \mathrm{CO}_{2} \mathrm{~m}^{-2} \mathrm{~s}^{-1}\right]}\end{array}$} & \multirow{2}{*}{$\begin{array}{l}\text { Std. Error } \\
R_{\mathrm{ECOO}}\end{array}$} & \multicolumn{2}{|c|}{ 95\% Confidence Limits } & \\
\hline & & & & $R_{\text {tot }}$ & $E_{0}$ & lower $R_{\text {eat }}$ & upper $R_{\text {eto }}$ & lower $E_{0}$ & upper $E_{0}$ & & & & & $\alpha$ & $G P P_{2000}$ & lower $\alpha$ & upper $a$ & $\begin{array}{l}\text { lower } \\
G P P_{2000}\end{array}$ & $\begin{array}{l}\text { upper } \\
G P P_{2000}\end{array}$ & & & & lower $R_{E \subset O}$ & upper $R_{E \in O}$ & $n$ \\
\hline A2C nigh & 2010-02-09 & - & - & - & - & - & - & - & - & - & - & - & - & - & - & - & - & - & - & - & 0.30 & 0.14 & 0.05 & 0.56 & 9 \\
\hline A2C $\mathrm{Cinh}_{\text {igh }}$ & 2010-02-25 & - & - & - & - & - & - & - & - & - & - & - & - & - & - & - & - & - & - & - & 0.15 & 0.04 & 0.07 & 0.23 & 9 \\
\hline A2C nigh & 2010-03-08 & - & - & - & - & - & - & - & - & - & - & - & - & - & - & - & - & - & - & - & 1.07 & 0.09 & 0.90 & 1.25 & 9 \\
\hline $\mathrm{A} 2 \mathrm{C}_{\text {nigh }}$ & 2010-03-24 & 2.49 & 76.95 & 0.07 & 13.88 & 2.34 & 2.64 & 48.53 & 105.38 & 30 & $T_{\text {air }}$ & 0.00 & -2.46 & 0.00 & 0.12 & -0.01 & 0.00 & -2.71 & -2.21 & 44 & - & - & - & - & - \\
\hline $\mathrm{A} 2 \mathrm{C}_{\text {nigh }}$ & 2010-04-06 & 7.03 & 144.14 & 0.56 & 52.92 & 5.85 & 8.21 & 32.50 & 255.78 & 19 & $T_{\text {air }}$ & - & - & - & - & - & - & - & - & - & - & - & - & - & - \\
\hline $\mathrm{A} 2 \mathrm{C}_{\text {nigh }}$ & 2010-04-28 & 8.78 & 113.36 & 0.83 & 33.95 & 6.97 & 10.60 & 39.39 & 187.32 & 14 & $T_{\text {air }}$ & -0.01 & -8.95 & 0.00 & 0.61 & -0.02 & -0.01 & -10.24 & -7.65 & 17 & - & - & - & - & - \\
\hline $\mathrm{A} 2 \mathrm{C}_{\text {ingh }}$ & $2010-05-23$ & 2.42 & 397.23 & 0.39 & 46.67 & 1.60 & 3.24 & 300.17 & 494.29 & 23 & $T_{\text {air }}$ & -0.04 & -22.39 & 0.00 & 0.34 & -0.04 & -0.03 & -23.08 & -21.70 & 30 & - & - & - & - & - \\
\hline A2C nigh & 2010-06-10 & 3.81 & 480.26 & 0.51 & 35.58 & 2.73 & 4.89 & 405.19 & 555.33 & 19 & $S T_{2}$ & -0.07 & -31.57 & 0.01 & 0.75 & -0.09 & -0.05 & -33.11 & -30.02 & 28 & - & - & - & - & - \\
\hline $\mathrm{A} 2 \mathrm{C}_{\text {igh }}$ & 2010-07-02 & 13.84 & 278.17 & 2.24 & 51.41 & 9.14 & 18.55 & 170.16 & 386.19 & 20 & $S T_{2}$ & -0.08 & -42.19 & 0.01 & 1.45 & -0.11 & -0.05 & -45.15 & -39.23 & 32 & - & - & - & - & - \\
\hline $\mathrm{A} 2 \mathrm{C}_{\mathrm{nigh}}$ & $2010-07-21$ & 20.09 & 61.88 & 1.20 & 14.67 & 17.55 & 22.64 & 30.77 & 92.99 & 18 & $T_{\text {air }}$ & -0.01 & -19.72 & 0.00 & 1.97 & -0.02 & -0.01 & -23.79 & -15.64 & 25 & - & - & - & - & - \\
\hline $\mathrm{A} 2 \mathrm{C}_{\text {nigh }}$ & $2010-08-21$ & - & - & - & - & - & - & - & - & - & - & -0.09 & -23.80 & 0.04 & 2.05 & -0.18 & 0.01 & -28.44 & -19.16 & 11 & 18.05 & 1.07 & 16.19 & 19.92 & 14 \\
\hline $\mathrm{A} 2 \mathrm{C}_{\mathrm{nigh}}$ & 2010-09-12 & - & - & - & - & - & - & - & - & - & - & - & - & - & - & - & - & - & - & - & 10.17 & 0.68 & 8.88 & 11.46 & 14 \\
\hline $\mathrm{A} \mathrm{C}_{\mathrm{nigh}}$ & 2010-10-04 & 4.94 & 277.42 & 0.90 & 77.83 & 2.96 & 6.91 & 106.12 & 448.72 & 13 & $T_{\text {air }}$ & -0.02 & -19.00 & 0.00 & 1.64 & -0.03 & -0.01 & 22.56 & -15.43 & 14 & - & - & - & - & - \\
\hline A2C $\mathrm{Cigh}_{\text {igh }}$ & $2010-10-13$ & 7.38 & 87.46 & 0.69 & 41.44 & 5.76 & 9.01 & 10.52 & 185.44 & 9 & $T_{\text {air }}$ & - & - & - & - & - & - & - & - & - & - & - & - & - & - \\
\hline $\mathrm{A} \mathrm{C}_{\mathrm{nigh}}$ & $2010-10-29$ & 5.12 & 127.75 & 0.25 & 26.17 & 4.57 & 5.67 & 70.73 & 184.78 & 14 & $T_{\text {air }}$ & -0.01 & -30.81 & 0.00 & 11.22 & -0.02 & -0.01 & -55.04 & -6.58 & 15 & - & - & - & - & - \\
\hline A2C $\mathrm{C}_{\text {ngh }}$ & $2010-12-13$ & - & - & - & - & - & - & - & - & - & - & - & - & - & - & - & - & - & - & - & 0.04 & 0.01 & 0.01 & 0.06 & 9 \\
\hline $\mathrm{A} 2 \mathrm{C}_{\mathrm{nigh}}$ & 2011-01-05 & - & - & - & - & - & - & - & - & - & - & - & - & - & - & - & - & - & - & - & 2.42 & 0.53 & 1.45 & 3.40 & 9 \\
\hline $\mathrm{A} 2 \mathrm{C}_{\mathrm{Cigh}}$ & $2011-01-27$ & - & - & - & - & - & - & - & - & - & - & - & - & - & - & - & - & - & - & - & 1.96 & 0.47 & 1.65 & 2.26 & 9 \\
\hline A2C nigh & 2011-02-07 & - & - & - & - & - & - & - & - & - & - & - & - & - & - & - & - & - & - & - & 1.55 & 0.07 & 1.43 & 1.68 & 15 \\
\hline $\mathrm{A} 2 \mathrm{C}_{\mathrm{nigh}}$ & $2011-03-08$ & 2.62 & 114.38 & 0.13 & 17.76 & 2.34 & 2.90 & 75.68 & 153.08 & 14 & $T_{\text {air }}$ & 0.00 & -0.70 & 0.00 & 0.11 & 0.00 & 0.00 & -0.95 & -0.45 & 13 & - & - & - & - & - \\
\hline $\mathrm{A} 2 \mathrm{C}_{\mathrm{ngh}}$ & $2011-03-29$ & 4.63 & 234.03 & 0.38 & 44.50 & 3.82 & 5.43 & 139.69 & 328.37 & 18 & $T_{\text {air }}$ & -0.02 & -15.01 & 0.00 & 0.70 & -0.02 & -0.01 & -16.46 & -13.56 & 23 & - & - & - & - & - \\
\hline $\mathrm{A} 2 \mathrm{C}_{\text {ing }}$ & $2011-04-20$ & 8.78 & 94.88 & 0.40 & 14.88 & 7.96 & 9.61 & 64.18 & 125.58 & 26 & $T_{\text {air }}$ & - & - & - & - & - & - & - & - & - & - & - & - & - & - \\
\hline A2C $\mathrm{C}_{\text {igh }}$ & 2011-05-06 & 4.69 & 69.13 & 0.17 & 13.36 & 4.34 & 5.05 & 40.94 & 97.32 & 19 & $T_{\text {air }}$ & - & - & - & - & - & - & - & - & - & - & - & - & - & - \\
\hline $\mathrm{A} 2 \mathrm{C}_{\text {igh }}$ & $2011-05-25$ & 6.91 & 84.23 & 0.18 & 9.25 & 6.53 & 7.30 & 64.61 & 103.85 & 18 & $T_{\text {air }}$ & 0.00 & -1.25 & 0.00 & 0.14 & -0.01 & 0.00 & -1.54 & -0.97 & 31 & - & - & - & - & - \\
\hline $\mathrm{A} 2 \mathrm{C}_{\text {nigh }}$ & $2011-06-28$ & 9.92 & 155.21 & 0.57 & 15.63 & 8.71 & 11.13 & 122.24 & 188.18 & 19 & $T_{\text {air }}$ & -0.04 & -39.75 & 0.01 & 1.17 & -0.06 & -0.03 & -33.97 & -42.21 & 20 & - & - & - & - & - \\
\hline $\mathrm{A} 2 \mathrm{C}_{\text {nigh }}$ & 2011-08-02 & 8.32 & 177.09 & 1.21 & 35.68 & 5.77 & 10.86 & 102.13 & 252.04 & 20 & $T_{\text {air }}$ & -0.11 & -69.31 & 0.03 & 2.86 & -0.17 & -0.05 & -75.28 & -63.34 & 22 & - & - & - & - & - \\
\hline $\mathrm{A} \mathrm{C}_{\mathrm{nigh}}$ & $2011-08-24$ & 17.70 & 120.30 & 2.27 & 29.64 & 12.80 & 22.59 & 56.27 & 184.33 & 15 & $T_{\text {air }}$ & -0.10 & -97.68 & 0.03 & 7.84 & -0.16 & -0.05 & -113.87 & -81.50 & 26 & - & - & - & - & - \\
\hline $\mathrm{A} 2 \mathrm{C}_{\text {nigh }}$ & $2011-09-24$ & 4.90 & 203.68 & 0.45 & 39.86 & 3.94 & 5.85 & 118.71 & 288.64 & 17 & $T_{\text {air }}$ & -0.02 & -23.07 & 0.00 & 2.18 & -0.03 & -0.01 & -27.68 & -18.47 & 19 & - & - & - & - & - \\
\hline $\mathrm{A} 2 \mathrm{C}_{\mathrm{ngh}}$ & 2011-10-16 & 3.47 & 108.54 & 0.10 & 17.64 & 3.26 & 3.67 & 71.31 & 145.76 & 18 & $T_{\text {air }}$ & -0.01 & -9.84 & 0.00 & 0.93 & -0.01 & -0.01 & -11.78 & -7.90 & 22 & - & - & - & - & - \\
\hline A2C $\mathrm{Cingh}_{\text {igh }}$ & 2011-12-15 & 3.50 & 98.86 & 0.36 & 41.42 & 2.66 & 4.35 & 0.92 & 196.81 & 9 & $T_{\text {air }}$ & -0.03 & -3.51 & 0.01 & 0.75 & -0.06 & 0.00 & -5.44 & -1.58 & 9 & - & - & - & - & - \\
\hline $\mathrm{A} 2 \mathrm{C}_{\text {noh h }}$ & 2012-01-12 & 1.80 & 144.11 & 0.11 & 29.54 & 1.55 & 2.05 & 80.29 & 207.93 & 15 & $T_{\text {air }}$ & -0.01 & -8.57 & 0.00 & 2.28 & -0.01 & 0.00 & -13.40 & -3.74 & 18 & - & - & - & - & - \\
\hline
\end{tabular}


Table S5 Model parameters of the $\mathrm{G} 1 \mathrm{C}_{\text {medium }}$ site.

\begin{tabular}{|c|c|c|c|c|c|c|c|c|c|c|c|c|c|c|c|c|c|c|c|c|c|c|c|c|c|}
\hline \multirow[b]{3}{*}{ Site } & \multirow[b]{3}{*}{ Date } & \multicolumn{10}{|l|}{$R_{\mathrm{E} c 0}$} & \multicolumn{9}{|l|}{$G P P$} & \multicolumn{5}{|l|}{$R_{\in \in O}$ without model } \\
\hline & & \multirow[b]{2}{*}{$R_{\text {iet }}$} & \multirow[b]{2}{*}{$E_{0}$} & \multicolumn{2}{|c|}{ Std. Error } & \multicolumn{4}{|c|}{$95 \%$ Confidence Limits } & \multirow[b]{2}{*}{$n$} & \multirow{2}{*}{$\begin{array}{l}\text { model } \\
\text { based on }\end{array}$} & \multirow[b]{2}{*}{$\alpha$} & \multicolumn{3}{|c|}{ Std. Error } & \multicolumn{4}{|c|}{ 95\% Confidence Limits } & \multirow[b]{2}{*}{$n$} & \multirow{2}{*}{$\begin{array}{l}\text { daily mean } R_{\mathrm{ECO}} \\
{\left[\mu \mathrm{mol} \mathrm{CO}_{2} \mathrm{~m}^{-2} \mathrm{~s}^{-1}\right]}\end{array}$} & \multirow{2}{*}{$\begin{array}{l}\text { Std. Error } \\
R_{E \in O}\end{array}$} & \multirow{2}{*}{\multicolumn{2}{|c|}{ 95\% Confidence Limits }} & \multirow[b]{2}{*}{$n$} \\
\hline & & & & $R_{\text {eft }}$ & $E_{0}$ & lower $R_{\text {iet }}$ & upper $R_{\text {eft }}$ & lower $E_{0}$ & upper $E_{0}$ & & & & $G P P_{2000}$ & $a$ & $G P P_{2000}$ & lower $\alpha$ & upper $a$ & $\begin{array}{l}\text { lower } \\
G P P_{2000}\end{array}$ & $\begin{array}{l}\text { upper } \\
G P P_{2000}\end{array}$ & & & & & upper $R_{\in \subset O}$ & \\
\hline $\mathrm{G}_{1} \mathrm{C}_{\text {medum }}$ & 2010-02-09 & - & - & - & - & - & - & - & - & - & - & - & - & - & - & - & - & - & - & - & 1.59 & 0.06 & 1.48 & 1.70 & 9 \\
\hline $\mathrm{G}_{1} \mathrm{C}_{\text {modum }}$ & $2010-03-08$ & - & - & - & - & - & - & - & - & - & - & - & - & - & - & - & - & - & - & - & 1.49 & 0.03 & 1.44 & 1.54 & 9 \\
\hline $\mathrm{G} 1 \mathrm{C}_{\text {medum }}$ & $2010-03-24$ & 5.56 & 51.60 & 0.13 & 10.16 & 5.26 & 5.86 & 27.59 & 75.62 & 9 & $T_{\text {air }}$ & -0.01 & -17.44 & 0.00 & 3.41 & -0.02 & -0.01 & -24.86 & -10.02 & 14 & - & - & - & - & - \\
\hline $\mathrm{G} 1 \mathrm{C}_{\text {medium }}$ & $2010-04-06$ & 6.96 & 445.87 & 0.35 & 76.92 & 6.19 & 7.72 & 279.70 & 612.04 & 15 & $S T_{2}$ & -0.01 & -36.01 & 0.00 & 5.56 & -0.01 & 0.00 & -47.61 & -24.41 & 22 & - & - & - & - & - \\
\hline $\mathrm{G}_{1} \mathrm{C}_{\text {medium }}$ & $2010-04-28$ & 15.08 & 181.18 & 0.90 & 33.49 & 13.16 & 16.99 & 109.80 & 252.56 & 17 & $S T_{2}$ & -0.05 & -43.75 & 0.00 & 1.19 & -0.06 & -0.04 & -46.26 & -41.24 & 20 & - & - & - & - & - \\
\hline $\mathrm{G}_{1} \mathrm{C}_{\text {medium }}$ & $2010-05-24$ & 10.99 & 301.17 & 0.51 & 29.03 & 9.92 & 12.06 & 239.63 & 362.70 & 18 & $S T_{2}$ & -0.07 & -47.56 & 0.00 & 0.56 & -0.08 & -0.06 & -48.73 & -46.38 & 22 & - & - & - & - & - \\
\hline $\mathrm{G}_{1} \mathrm{C}_{\text {medum }}$ & 2010-06-09 & 11.29 & 154.84 & 1.05 & 26.62 & 9.10 & 13.48 & 99.13 & 210.56 & 21 & $S T_{2}$ & -0.07 & -31.18 & 0.01 & 0.79 & -0.09 & -0.05 & -32.81 & -29.56 & 28 & - & - & - & - & - \\
\hline $\mathrm{G}_{1} \mathrm{C}_{\text {modium }}$ & 2010-07-07 & 5.76 & 467.71 & 1.28 & 74.30 & 3.05 & 8.47 & 310.95 & 624.47 & 19 & $S T_{5}$ & -0.04 & -31.64 & 0.01 & 1.37 & -0.06 & -0.02 & -34.51 & -28.77 & 21 & - & - & - & - & - \\
\hline $\mathrm{G}_{1} \mathrm{C}_{\text {metium }}$ & $2010-07-21$ & 15.52 & 275.53 & 2.15 & 41.54 & 10.99 & 20.05 & 188.26 & 362.80 & 20 & $S T_{2}$ & -0.05 & -36.69 & 0.02 & 2.80 & -0.08 & -0.02 & -42.45 & -30.93 & 27 & - & - & - & - & - \\
\hline $\mathrm{G}_{1} \mathrm{C}_{\text {medium }}$ & $2010-08-22$ & 15.85 & 72.27 & 0.52 & 7.49 & 14.73 & 16.97 & 56.20 & 88.34 & 16 & $T_{\text {air }}$ & -0.09 & -43.62 & 0.01 & 1.23 & -0.12 & -0.06 & -46.19 & -41.04 & 21 & - & - & - & - & - \\
\hline $\mathrm{G}_{1} \mathrm{C}_{\text {medum }}$ & 2010-09-11 & 9.99 & 146.57 & 0.40 & 14.49 & 9.14 & 10.84 & 116.01 & 177.13 & 19 & $T_{\text {air }}$ & -0.10 & -40.60 & 0.01 & 0.70 & -0.12 & -0.08 & -42.05 & -39.15 & 26 & - & - & - & - & - \\
\hline $\mathrm{G}_{1} \mathrm{C}_{\text {medum }}$ & $2010-10-29$ & 7.76 & 135.15 & 0.44 & 33.85 & 6.81 & 8.70 & 62.02 & 208.28 & 15 & $T_{\text {air }}$ & -0.02 & -39.42 & 0.00 & 7.00 & -0.03 & -0.01 & -54.27 & -24.57 & 18 & - & - & - & - & - \\
\hline $\mathrm{G}_{1} \mathrm{C}_{\text {medium }}$ & $2010-12-16$ & - & - & - & - & - & - & - & - & - & - & - & - & - & - & - & - & - & - & - & 1.05 & 0.06 & 0.94 & 1.17 & 9 \\
\hline $\mathrm{G}_{1} \mathrm{C}_{\text {medium }}$ & 2011-01-05 & - & - & - & - & - & - & - & - & - & - & - & - & - & - & - & - & - & - & - & 4.47 & 0.61 & 3.35 & 5.59 & 9 \\
\hline $\mathrm{G}_{1} \mathrm{C}_{\text {medium }}$ & $2011-01-27$ & - & - & - & - & - & - & - & - & - & - & - & - & - & - & - & - & - & - & - & 2.15 & 0.12 & 1.94 & 2.37 & 9 \\
\hline $\mathrm{G}_{1} \mathrm{C}_{\text {medium }}$ & 2011-02-07 & 2.45 & 88.93 & 0.11 & 22.55 & 2.20 & 2.69 & 39.80 & 138.06 & 14 & $T_{\text {air }}$ & 0.00 & -1.86 & 0.00 & 0.95 & -0.01 & 0.00 & -4.30 & 0.57 & 7 & - & - & - & - & - \\
\hline $\mathrm{G}_{1} \mathrm{C}_{\text {modum }}$ & 2011-03-09 & 6.23 & 275.39 & 1.00 & 52.83 & 4.13 & 8.34 & 164.39 & 386.38 & 20 & $S T_{2}$ & 0.00 & -4.13 & 0.00 & 0.32 & -0.01 & 0.00 & -4.80 & -3.46 & 23 & - & - & - & - & - \\
\hline $\mathrm{G}_{1} \mathrm{C}_{\text {medium }}$ & 2011-03-29 & 7.86 & 273.58 & 0.32 & 36.32 & 7.19 & 8.53 & 196.94 & 350.21 & 19 & $S T_{2}$ & -0.02 & -20.96 & 0.00 & 0.71 & -0.02 & -0.02 & -22.42 & -19.50 & 28 & - & - & - & - & - \\
\hline $\mathrm{G}_{1} \mathrm{C}_{\text {medum }}$ & $2011-04-20$ & 12.07 & 108.27 & 0.54 & 16.87 & 10.95 & 13.19 & 72.97 & 143.58 & 21 & $T_{\text {air }}$ & -0.04 & -31.53 & 0.01 & 1.33 & -0.06 & -0.03 & -34.26 & -28.80 & 30 & - & - & - & - & - \\
\hline $\mathrm{G}_{1} \mathrm{C}_{\text {medium }}$ & $2011-05-10$ & 17.04 & 139.74 & 0.59 & 14.65 & 15.81 & 18.28 & 109.08 & 170.39 & 21 & $S T_{2}$ & -0.04 & -37.61 & 0.01 & 1.32 & -0.05 & -0.03 & -40.31 & -34.91 & 31 & - & - & - & - & - \\
\hline $\mathrm{GlC}_{\text {medium }}$ & $2011-06-21$ & 7.30 & 428.58 & 1.09 & 89.72 & 4.64 & 9.96 & 209.05 & 648.11 & 12 & $S T_{10}$ & -0.08 & -45.56 & 0.01 & 1.71 & -0.11 & -0.06 & -49.22 & -41.90 & 16 & - & - & - & - & - \\
\hline $\mathrm{G}_{1} \mathrm{C}_{\text {medum }}$ & $2011-06-28$ & 15.68 & 132.75 & 1.68 & 27.44 & 12.17 & 19.19 & 75.31 & 190.19 & 21 & $T_{\text {air }}$ & -0.08 & -45.52 & 0.01 & 0.98 & -0.10 & -0.06 & -47.53 & -43.51 & 30 & - & - & - & - & - \\
\hline $\mathrm{G}_{1} \mathrm{C}_{\text {medum }}$ & 2011-07-26 & 13.64 & 100.63 & 0.63 & 14.36 & 12.35 & 14.93 & 70.98 & 130.27 & 26 & $T_{\text {air }}$ & -0.09 & -41.98 & 0.01 & 0.91 & -0.11 & -0.07 & -43.82 & -40.14 & 35 & - & - & - & - & - \\
\hline $\mathrm{G}_{1} \mathrm{C}_{\text {medum }}$ & 2011-08-17 & 15.17 & 77.85 & 0.57 & 10.18 & 13.97 & 16.38 & 56.36 & 99.34 & 19 & $T_{\text {air }}$ & -0.08 & -42.61 & 0.01 & 0.93 & -0.10 & -0.06 & -44.51 & -40.71 & 29 & - & - & - & - & - \\
\hline $\mathrm{G}_{1} \mathrm{C}_{\text {medium }}$ & 2011-09-16 & 13.34 & 52.50 & 0.30 & 7.79 & 12.70 & 13.98 & 35.99 & 69.01 & 18 & $T_{\text {air }}$ & -0.03 & -11.37 & 0.01 & 1.05 & -0.05 & 0.00 & -13.55 & -9.19 & 22 & - & - & - & - & - \\
\hline $\mathrm{G}_{1} \mathrm{C}_{\text {medium }}$ & $2011-10-16$ & 9.60 & 177.01 & 0.20 & 19.33 & 9.17 & 10.02 & 136.22 & 217.80 & 19 & $S T_{2}$ & -0.03 & -40.11 & 0.00 & 2.74 & -0.04 & -0.02 & -45.83 & -34.39 & 22 & - & - & - & - & - \\
\hline $\mathrm{G}_{1} \mathrm{C}_{\text {medum }}$ & $2011-12-15$ & - & - & - & - & - & - & - & - & - & - & -0.07 & -10.65 & 0.03 & 3.29 & -0.15 & 0.01 & -18.71 & -2.58 & 8 & 4.19 & 0.31 & 3.61 & 4.77 & 9 \\
\hline $\mathrm{G}_{1} \mathrm{C}_{\text {medum }}$ & 2012-01-12 & 10.80 & 447.23 & 2.23 & 73.24 & 5.95 & 15.66 & 287.65 & 606.81 & 14 & $S T_{2}$ & -0.02 & -15.99 & 0.01 & 8.09 & -0.03 & 0.00 & -33.63 & 1.64 & 14 & - & _ & - & - & - \\
\hline
\end{tabular}


Table S6 Model parameters of the G1Chigh site.

\begin{tabular}{|c|c|c|c|c|c|c|c|c|c|c|c|c|c|c|c|c|c|c|c|c|c|c|c|c|c|}
\hline \multirow[b]{3}{*}{ Site } & \multirow[b]{3}{*}{ Date } & \multicolumn{10}{|l|}{$R_{E \subset O O}$} & \multicolumn{9}{|l|}{ GPP } & \multicolumn{5}{|l|}{$R_{E \in c o}$ without model } \\
\hline & & \multirow[b]{2}{*}{$R_{\text {ief }}$} & \multirow[b]{2}{*}{$E_{0}$} & \multicolumn{2}{|c|}{ Std. Error } & \multicolumn{4}{|c|}{$95 \%$ Confidence Limits } & \multirow[b]{2}{*}{$n$} & \multirow[b]{2}{*}{$\begin{array}{l}\text { model } \\
\text { based on }\end{array}$} & \multirow[b]{2}{*}{$a$} & \multicolumn{3}{|c|}{ Std. Error } & \multicolumn{4}{|c|}{ 95\% Confidence Limits } & \multirow[b]{2}{*}{$n$} & \multirow{2}{*}{$\begin{array}{l}\text { daily mean } R_{\mathrm{Eco}} \\
{\left[\mu \mathrm{mol} \mathrm{CO}_{2} \mathrm{~m}^{-2} \mathrm{~s}^{-1}\right]}\end{array}$} & \multirow{2}{*}{$\begin{array}{l}\text { Std. Error } \\
R_{E \in C O}\end{array}$} & \multicolumn{2}{|c|}{$95 \%$ Confidence Limits } & \multirow[b]{2}{*}{$n$} \\
\hline & & & & $R_{\text {tet }}$ & $E_{0}$ & lower $R_{\text {ift }}$ & upper $R_{\text {iet }}$ & lower $E_{0}$ & upper $E_{0}$ & & & & $G P P_{2000}$ & $\alpha$ & $G P P_{2000}$ & lower $\alpha$ & upper $a$ & $\begin{array}{ll}\text { lower } \\
G P P_{2000} \\
\end{array}$ & $\begin{array}{l}u_{\text {upper }} \\
G P P_{2000}\end{array}$ & & & & lower $R_{E \subset c o}$ & upper $R_{E \subset O O}$ & \\
\hline Gicingh & 2010-02-09 & - & - & - & - & - & - & - & - & - & - & - & - & - & - & - & - & - & - & - & 1.26 & 0.88 & 1.02 & 1.50 & 6 \\
\hline G1Chigh & 2010-03-08 & - & - & - & - & - & - & - & - & - & - & - & - & - & - & - & - & - & - & - & 1.21 & 0.09 & 1.05 & 1.38 & 9 \\
\hline G1C nigh & $2010-03-24$ & 4.87 & 40.00 & 0.20 & 13.63 & 4.45 & 5.28 & 10.95 & 69.06 & 17 & $T_{\text {air }}$ & -0.02 & -8.91 & 0.01 & 0.47 & -0.03 & -0.01 & -9.88 & -7.94 & 27 & - & - & - & - & - \\
\hline G1Chigh & 2010-04-06 & 7.75 & 110.35 & 0.61 & 38.27 & 6.46 & 9.05 & 28.78 & 191.92 & 17 & $T_{\text {air }}$ & -0.02 & -25.30 & 0.00 & 1.27 & -0.02 & -0.01 & -27.94 & -22.65 & 22 & - & - & - & - & - \\
\hline G1C nigh & $2010-04-28$ & 11.39 & 63.78 & 0.53 & 16.12 & 10.26 & 12.53 & 29.20 & 98.36 & 16 & $T_{\text {air }}$ & -0.03 & -36.67 & 0.01 & 1.48 & -0.04 & -0.02 & -39.79 & -33.55 & 20 & - & - & - & - & - \\
\hline $\mathrm{G}_{1 C_{\text {nigh }}}$ & $2010-05-24$ & 8.94 & 351.02 & 0.72 & 52.71 & 7.36 & 10.51 & 235.00 & 467.04 & 13 & $S T_{2}$ & -0.04 & -51.43 & 0.00 & 1.31 & -0.05 & -0.03 & -54.17 & -48.68 & 20 & - & - & - & - & - \\
\hline G1C nigh & 2010-06-09 & 15.58 & 91.65 & 1.92 & 33.23 & 11.54 & 19.61 & 21.83 & 161.48 & 20 & $T_{\text {air }}$ & -0.10 & -36.43 & 0.01 & 0.66 & -0.12 & -0.08 & -37.78 & -35.08 & 27 & - & - & - & - & - \\
\hline $\mathrm{G}_{1 C_{\text {nigh }}}$ & $2010-07-07$ & 15.79 & 85.17 & 0.99 & 20.65 & 13.65 & 17.93 & 40.56 & 129.78 & 15 & $T_{\text {air }}$ & -0.06 & -39.26 & 0.01 & 0.98 & -0.07 & -0.04 & -41.32 & -37.20 & 21 & - & - & - & - & - \\
\hline G1C $C_{\text {nigh }}$ & 2010-07-21 & 16.78 & 107.93 & 1.38 & 18.93 & 13.69 & 19.86 & 65.75 & 150.10 & 12 & $T_{\text {air }}$ & -0.07 & -38.41 & 0.01 & 1.40 & -0.09 & -0.04 & -41.43 & -35.39 & 15 & - & - & - & - & - \\
\hline G1 Cligh & 2010-08-22 & 20.25 & 58.29 & 1.73 & 19.61 & 16.57 & 23.94 & 16.49 & 100.09 & 17 & $T_{\text {air }}$ & -0.08 & -46.19 & 0.01 & 1.45 & -0.11 & -0.06 & -49.20 & -43.18 & 23 & - & - & - & - & - \\
\hline $\mathrm{G}_{1 \mathrm{C}_{\text {ngh }}}$ & 2010-09-11 & 13.45 & 116.83 & 0.54 & 14.92 & 12.29 & 14.60 & 85.04 & 148.63 & 17 & $T_{\text {air }}$ & -0.10 & -39.34 & 0.01 & 0.55 & -0.11 & -0.08 & -40.47 & -38.22 & 29 & - & - & - & - & - \\
\hline G1 $C_{\text {non }}$ & $2010-10-29$ & 6.24 & 111.28 & 0.19 & 14.32 & 5.83 & 6.64 & 80.34 & 142.21 & 15 & $T_{\text {air }}$ & -0.02 & -36.79 & 0.00 & 4.99 & -0.03 & -0.02 & -47.56 & -26.02 & 15 & - & - & - & - & - \\
\hline $\mathrm{G}_{1 \text { non }}$ & $2010-12-16$ & - & - & - & - & - & - & - & - & - & - & - & - & - & - & - & - & - & - & - & 2.45 & 0.46 & 1.60 & 3.30 & 9 \\
\hline G1C nigh & $2011-01-05$ & - & - & - & - & - & - & - & - & - & - & - & - & - & - & - & - & - & - & - & 2.13 & 0.45 & 1.35 & 2.91 & 9 \\
\hline $\mathrm{G}_{1 C_{\text {nigh }}}$ & $2011-01-27$ & - & - & - & - & - & - & - & - & - & - & - & - & - & - & - & - & - & - & - & 2.16 & 0.18 & 1.82 & 2.50 & 9 \\
\hline G1C nigh & 2011-02-07 & 2.23 & 113.41 & 0.14 & 32.98 & 1.93 & 2.52 & 43.49 & 183.34 & 18 & $T_{\text {air }}$ & 0.00 & -5.11 & 0.00 & 0.73 & 0.00 & 0.00 & -6.68 & -3.54 & 15 & - & - & - & - & - \\
\hline G1C cingh & 2011-03-08 & 2.45 & 82.00 & 0.16 & 21.30 & 2.10 & 2.80 & 36.61 & 127.40 & 17 & $T_{\text {air }}$ & 0.00 & -4.85 & 0.00 & 0.59 & 0.00 & 0.00 & -6.10 & -3.61 & 19 & - & - & - & - & - \\
\hline G1Chigh & 2011-03-29 & 8.98 & 159.99 & 0.42 & 25.77 & 8.10 & 9.86 & 105.61 & 214.37 & 19 & $T_{\text {air }}$ & -0.03 & -25.07 & 0.00 & 0.85 & -0.04 & -0.02 & -26.83 & -23.31 & 24 & - & - & - & - & - \\
\hline G1C nigh & $2011-04-20$ & 12.36 & 339.75 & 0.72 & 53.59 & 10.83 & 13.88 & 227.16 & 452.35 & 20 & $S T_{2}$ & -0.04 & -40.50 & 0.00 & 1.27 & -0.05 & -0.03 & -43.11 & -37.89 & 27 & - & - & - & - & - \\
\hline G1C nigh & $2011-05-10$ & 15.68 & 112.87 & 1.13 & 21.06 & 13.32 & 18.05 & 68.94 & 156.80 & 22 & $T_{\text {air }}$ & -0.10 & -51.21 & 0.01 & 0.80 & -0.11 & -0.08 & -52.85 & -49.58 & 29 & - & - & - & - & - \\
\hline G1C & $2011-06-21$ & 7.49 & 416.41 & 1.63 & 91.65 & 3.87 & 11.12 & 212.20 & 620.62 & 12 & $S T_{2}$ & -0.07 & -48.31 & 0.01 & 1.71 & -0.09 & -0.06 & -51.96 & -44.66 & 17 & - & - & - & - & - \\
\hline G1C nigh & $2011-06-28$ & 17.60 & 83.62 & 0.88 & 12.42 & 15.78 & 19.41 & 57.86 & 109.39 & 24 & $T_{\text {air }}$ & -0.13 & -43.58 & 0.02 & 0.78 & -0.16 & -0.10 & -45.18 & -41.99 & 32 & - & - & - & - & - \\
\hline G1 Cligh & 2011-07-26 & 9.48 & 355.18 & 0.68 & 39.94 & 8.05 & 10.90 & 271.57 & 438.78 & 21 & $S T_{2}$ & -0.09 & -43.69 & 0.01 & 0.79 & -0.11 & -0.08 & -45.29 & -42.08 & 35 & - & - & - & - & - \\
\hline G1 Chigh $_{\text {na }}$ & 2011-08-18 & 11.24 & 219.60 & 1.16 & 34.20 & 8.80 & 13.68 & 147.74 & 291.46 & 20 & $S T_{2}$ & -0.09 & -42.79 & 0.01 & 0.68 & -0.11 & -0.07 & -44.19 & -41.39 & 28 & - & - & - & - & - \\
\hline $\mathrm{G}_{1 \mathrm{C}_{\text {nigh }}}$ & $2011-09-16$ & 7.45 & 285.14 & 0.49 & 48.61 & 6.42 & 8.48 & 183.02 & 387.26 & 20 & $S T_{5}$ & -0.01 & -9.15 & 0.01 & 1.06 & -0.03 & 0.00 & -11.35 & -6.95 & 24 & - & - & - & - & - \\
\hline G1C nigh & $2011-10-16$ & 8.24 & 437.52 & 0.60 & 113.76 & 6.85 & 9.62 & 175.19 & 699.84 & 10 & $S T_{5}$ & -0.03 & -27.09 & 0.00 & 1.05 & -0.03 & -0.02 & -29.37 & -24.81 & 14 & - & - & - & - & - \\
\hline $\mathrm{G}_{1 \text { nigh }}$ & 2011-12-15 & - & - & - & - & - & - & - & - & - & - & -0.06 & -15.15 & 0.01 & 3.28 & -0.08 & -0.04 & 22.91 & -7.39 & 9 & 2.98 & 0.31 & 2.40 & 3.55 & 9 \\
\hline $\mathrm{G}_{1} \mathrm{C}_{\text {noh }}$ & 2012-01-12 & 13.31 & 525.53 & 3.73 & 127.91 & 5.18 & 21.45 & 246.82 & 804.23 & 14 & $S T_{2}$ & -0.03 & -23.67 & 0.00 & 1.76 & -0.03 & -0.02 & -27.51 & -19.82 & 14 & - & - & - & - & - \\
\hline
\end{tabular}


Table S7 Model parameters of the $\mathrm{G}_{2} \mathrm{C}_{\text {medium }}$ site.

\begin{tabular}{|c|c|c|c|c|c|c|c|c|c|c|c|c|c|c|c|c|c|c|c|c|c|c|c|c|c|}
\hline \multirow[b]{3}{*}{ Site } & \multirow[b]{3}{*}{ Date } & \multicolumn{10}{|l|}{$R_{\mathrm{E} c 0}$} & \multicolumn{9}{|l|}{$G P P$} & \multicolumn{5}{|l|}{$R_{\in \in O}$ without model } \\
\hline & & \multirow[b]{2}{*}{$R_{\text {iet }}$} & \multirow[b]{2}{*}{$E_{0}$} & \multicolumn{2}{|c|}{ Std. Error } & \multicolumn{4}{|c|}{$95 \%$ Confidence Limits } & \multirow[b]{2}{*}{$n$} & \multirow{2}{*}{$\begin{array}{c}\text { model } \\
\text { based on }\end{array}$} & \multirow[b]{2}{*}{$\alpha$} & \multicolumn{3}{|c|}{ Std. Error } & \multicolumn{4}{|c|}{ 95\% Confidence Limits } & \multirow[b]{2}{*}{$n$} & \multirow{2}{*}{$\begin{array}{l}\text { daily mean } R_{\mathrm{ECO}} \\
{\left[\mu \mathrm{mol} \mathrm{CO}_{2} \mathrm{~m}^{-2} \mathrm{~s}^{-1}\right]}\end{array}$} & \multirow{2}{*}{$\begin{array}{l}\text { Std. Error } \\
R_{E \in O}\end{array}$} & \multirow{2}{*}{\multicolumn{2}{|c|}{ 95\% Confidence Limits }} & \multirow[b]{2}{*}{$n$} \\
\hline & & & & $R_{\text {eft }}$ & $E_{0}$ & lower $R_{\text {iet }}$ & upper $R_{\text {eft }}$ & lower $E_{0}$ & upper $E_{0}$ & & & & $G P P_{2000}$ & $a$ & $G P P_{2000}$ & lower $\alpha$ & upper $a$ & $\begin{array}{l}\text { lower } \\
G P P_{2000}\end{array}$ & $\begin{array}{l}\text { upper } \\
G P P_{2000}\end{array}$ & & & & & & \\
\hline $\mathrm{G}^{2} \mathrm{C}_{\text {medum }}$ & 2010-02-09 & - & - & - & - & - & - & - & - & - & - & - & - & - & - & - & - & - & - & - & 1.53 & 0.09 & 1.36 & 1.71 & 6 \\
\hline $\mathrm{G} 2 \mathrm{C}_{\text {modum }}$ & $2010-03-08$ & - & - & - & - & - & - & - & - & - & - & - & - & - & - & - & - & - & - & - & 2.14 & 0.16 & 1.85 & 2.43 & 9 \\
\hline $\mathrm{G} 2 \mathrm{C}_{\text {medum }}$ & $2010-03-24$ & 5.65 & 72.15 & 0.12 & 11.65 & 5.36 & 5.94 & 44.61 & 99.69 & 9 & $T_{\text {air }}$ & -0.01 & -16.82 & 0.00 & 3.81 & -0.01 & -0.01 & -25.06 & -8.58 & 15 & - & - & - & - & - \\
\hline G2 $\mathrm{C}_{\text {medium }}$ & $2010-04-06$ & 7.19 & 419.60 & 0.26 & 47.88 & 6.63 & 7.74 & 318.09 & 521.11 & 18 & $S T_{2}$ & -0.01 & -34.75 & 0.00 & 4.77 & -0.01 & 0.00 & -44.69 & -24.80 & 22 & - & - & - & - & - \\
\hline $\mathrm{G} \mathrm{C}_{\text {medium }}$ & 2010-04-28 & 11.73 & 191.24 & 0.95 & 28.69 & 9.71 & 13.74 & 130.09 & 252.39 & 17 & $T_{\text {air }}$ & -0.04 & -45.59 & 0.01 & 3.03 & -0.05 & -0.02 & -51.99 & -39.20 & 19 & - & - & - & - & - \\
\hline $\mathrm{G} 2 \mathrm{C}_{\text {medum }}$ & $2010-05-24$ & 13.14 & 93.72 & 0.52 & 11.74 & 12.03 & 14.25 & 68.84 & 118.61 & 18 & $T_{\text {air }}$ & -0.08 & -52.31 & 0.01 & 1.03 & -0.10 & -0.07 & -54.44 & -50.17 & 22 & - & - & - & - & - \\
\hline G2C madum & 2010-06-09 & 11.75 & 109.05 & 1.14 & 25.24 & 9.31 & 14.18 & 54.91 & 163.19 & 16 & $T_{\text {air }}$ & -0.07 & -26.29 & 0.01 & 0.79 & -0.09 & -0.04 & -27.93 & -24.66 & 25 & - & - & - & - & - \\
\hline $\mathrm{G} \mathrm{C}_{\text {medium }}$ & 2010-07-07 & - & - & - & - & - & - & - & - & - & - & -0.14 & -31.20 & 0.04 & 1.30 & -0.22 & -0.06 & -33.93 & -28.46 & 20 & 20.37 & 0.86 & 18.72 & 22.01 & 18 \\
\hline $\mathrm{G} 2 \mathrm{C}_{\text {mestium }}$ & $2010-07-21$ & 19.26 & 112.06 & 1.64 & 21.33 & 14.99 & 23.53 & 56.20 & 167.93 & 20 & $T_{\text {air }}$ & -0.05 & -32.41 & 0.02 & 4.16 & -0.09 & 0.00 & -41.02 & -23.80 & 25 & - & - & - & - & - \\
\hline G2C $\mathrm{C}_{\text {modum }}$ & $2010-08-22$ & 11.75 & 273.86 & 1.02 & 37.89 & 9.59 & 13.91 & 193.53 & 354.19 & 18 & $S T_{5}$ & -0.10 & -42.30 & 0.01 & 0.80 & -0.12 & -0.08 & -43.97 & -40.63 & 21 & - & - & - & - & - \\
\hline $\mathrm{G} \mathrm{C}_{\text {medium }}$ & 2010-09-11 & 10.70 & 106.79 & 0.41 & 14.14 & 9.84 & 11.57 & 76.96 & 136.63 & 19 & $T_{\text {air }}$ & -0.12 & -39.73 & 0.01 & 0.52 & -0.14 & -0.10 & -40.81 & -38.64 & 26 & - & - & - & - & - \\
\hline $\mathrm{G} 2 \mathrm{C}_{\text {medum }}$ & $2010-10-29$ & 8.51 & 222.39 & 0.48 & 40.84 & 7.48 & 9.55 & 134.17 & 310.61 & 15 & $S T_{2}$ & -0.03 & -42.97 & 0.00 & 5.23 & -0.03 & -0.02 & -54.01 & -31.94 & 19 & - & - & - & - & - \\
\hline $\mathrm{G} \mathrm{C}_{\text {medium }}$ & $2010-12-16$ & - & - & - & - & - & - & - & - & - & - & - & - & - & - & - & - & - & - & - & 1.44 & 0.12 & 1.22 & 1.66 & 9 \\
\hline $\mathrm{G} 2 \mathrm{C}_{\text {modium }}$ & 2011-01-05 & - & - & - & - & - & - & - & - & - & - & - & - & - & - & - & - & - & - & - & 3.26 & 0.40 & 2.52 & 4.01 & 9 \\
\hline G2C $\mathrm{C}_{\text {modum }}$ & $2011-01-27$ & - & - & - & - & - & - & - & - & - & - & - & - & - & - & - & - & - & - & - & 2.30 & 0.09 & 2.14 & 2.46 & 9 \\
\hline $\mathrm{G} 2 \mathrm{C}_{\text {medium }}$ & 2011-02-07 & 2.31 & 29.03 & 0.05 & 9.46 & 2.20 & 2.42 & 8.20 & 49.86 & 13 & $T_{\text {air }}$ & 0.00 & -3.29 & 0.00 & 2.12 & -0.01 & 0.00 & -7.88 & 1.29 & 15 & - & - & - & - & - \\
\hline $\mathrm{G} 2 \mathrm{C}_{\text {medium }}$ & 2011-03-09 & 9.46 & 387.53 & 2.50 & 87.27 & 4.16 & 14.76 & 202.53 & 572.54 & 18 & $S T_{2}$ & 0.00 & -3.58 & 0.00 & 0.69 & -0.01 & 0.00 & -5.02 & -2.14 & 23 & - & - & - & - & - \\
\hline $\mathrm{G} 2 \mathrm{C}_{\text {medium }}$ & 2011-03-29 & 7.33 & 265.06 & 0.18 & 21.50 & 6.96 & 7.71 & 220.06 & 310.05 & 21 & $S T_{2}$ & -0.02 & -25.22 & 0.00 & 0.89 & -0.03 & -0.02 & -27.04 & -23.40 & 28 & - & - & - & - & - \\
\hline $\mathrm{G}^{2} \mathrm{C}_{\text {medum }}$ & $2011-04-20$ & 11.59 & 171.79 & 0.39 & 19.77 & 10.78 & 12.40 & 130.55 & 213.03 & 22 & $S T_{2}$ & -0.04 & -42.66 & 0.00 & 1.46 & -0.05 & -0.03 & -45.65 & -39.66 & 29 & - & - & - & - & - \\
\hline $\mathrm{G} \mathrm{C}_{\text {medium }}$ & $2011-05-10$ & 17.16 & 73.71 & 0.67 & 11.51 & 15.78 & 18.54 & 49.90 & 97.53 & 25 & $T_{\text {air }}$ & -0.08 & -45.86 & 0.01 & 1.39 & -0.11 & -0.06 & -48.71 & -43.00 & 31 & - & - & - & - & - \\
\hline G2C $\mathrm{C}_{\text {medium }}$ & $2011-06-21$ & 11.94 & 216.47 & 0.91 & 29.21 & 9.95 & 13.93 & 152.83 & 280.10 & 14 & $S T_{2}$ & -0.10 & -62.80 & 0.01 & 2.04 & -0.12 & -0.07 & -67.21 & -58.40 & 15 & - & - & - & - & - \\
\hline G2C $\mathrm{C}_{\text {modum }}$ & $2011-06-28$ & 17.53 & 95.90 & 0.82 & 12.36 & 15.83 & 19.22 & 70.26 & 121.53 & 24 & $T_{\text {air }}$ & -0.13 & -48.98 & 0.01 & 0.91 & -0.16 & -0.10 & -50.84 & -47.12 & 32 & - & - & - & - & - \\
\hline G2C medum & 2011-07-26 & 9.43 & 340.97 & 0.56 & 28.40 & 8.28 & 10.58 & 282.35 & 399.59 & 26 & $S T_{2}$ & -0.11 & -41.73 & 0.01 & 0.69 & -0.13 & -0.09 & -43.14 & -40.31 & 35 & - & - & - & - & - \\
\hline $\mathrm{G} 2 \mathrm{C}_{\text {medum }}$ & 2011-08-17 & 14.31 & 126.80 & 1.45 & 29.90 & 11.27 & 17.35 & 63.99 & 189.61 & 20 & $S T_{2}$ & -0.10 & -47.49 & 0.01 & 0.57 & -0.12 & -0.09 & -48.66 & -46.31 & 26 & - & - & - & - & - \\
\hline $\mathrm{G} \mathrm{C}_{\text {medium }}$ & 2011-09-16 & 13.49 & 102.46 & 0.44 & 10.71 & 12.57 & 14.40 & 79.96 & 124.96 & 20 & $T_{\text {air }}$ & -0.01 & -14.22 & 0.00 & 1.23 & -0.02 & -0.01 & -16.79 & -11.65 & 22 & - & - & - & - & - \\
\hline $\mathrm{G} \mathrm{C}_{\text {medium }}$ & $2011-10-16$ & 10.69 & 71.95 & 0.13 & 6.59 & 10.41 & 10.97 & 58.04 & 85.86 & 19 & $T_{\text {air }}$ & -0.05 & -38.23 & 0.01 & 1.73 & -0.07 & -0.04 & -41.83 & -34.62 & 22 & - & - & - & - & - \\
\hline G2C medum & $2011-12-15$ & - & - & - & - & - & - & - & - & - & - & -0.08 & -10.96 & 0.03 & 2.57 & -0.14 & -0.01 & -17.26 & -4.67 & 8 & 4.15 & 0.42 & 3.36 & 4.93 & 9 \\
\hline $\mathrm{G}_{2} \mathrm{C}_{\text {modum }}$ & 2012-01-12 & 3.97 & 153.98 & 0.67 & 64.04 & 2.33 & 5.62 & -2.72 & 310.67 & 8 & $T_{\text {air }}$ & -0.03 & -14.57 & 0.00 & 1.33 & -0.03 & -0.02 & -18.80 & -10.33 & 5 & - & _ & - & - & - \\
\hline
\end{tabular}


Table S8 Model parameters of the G2Chigh site.

\begin{tabular}{|c|c|c|c|c|c|c|c|c|c|c|c|c|c|c|c|c|c|c|c|c|c|c|c|c|c|}
\hline \multirow[b]{3}{*}{ Site } & \multirow[b]{3}{*}{ Date } & \multicolumn{10}{|l|}{$R_{\mathrm{E} C \mathrm{O}}$} & \multicolumn{9}{|l|}{ GPP } & \multicolumn{5}{|l|}{$R_{E \in O}$ without model } \\
\hline & & \multirow[b]{2}{*}{$R_{\text {tet }}$} & \multirow[b]{2}{*}{$E_{0}$} & \multicolumn{2}{|c|}{ Std. Error } & \multicolumn{4}{|c|}{$95 \%$ Confidence Limits } & \multirow[b]{2}{*}{$n$} & \multirow{2}{*}{$\begin{array}{c}\text { model } \\
\text { based on }\end{array}$} & \multirow[b]{2}{*}{$\alpha$} & \multirow[b]{2}{*}{$G P P_{2000}$} & \multicolumn{2}{|c|}{ Std. Error } & \multicolumn{4}{|c|}{ 95\% Confidence Limits } & \multirow[b]{2}{*}{$n$} & \multirow{2}{*}{ 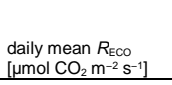 } & \multirow{2}{*}{$\begin{array}{l}\text { Std. Error } \\
R_{E \subset 0}\end{array}$} & \multicolumn{2}{|c|}{ 95\% Confidence Limits } & \multirow[b]{2}{*}{$n$} \\
\hline & & & & $R_{\text {eft }}$ & $E_{0}$ & lower $R_{\text {tet }}$ & upper $R_{\text {ref }}$ & lower $E_{0}$ & upper $E_{0}$ & & & & & $\alpha$ & $G P P_{2000}$ & lower $\alpha$ & upper $\alpha$ & $\begin{array}{l}\text { lower } \\
G P P_{2000}\end{array}$ & $\begin{array}{l}\text { upper } \\
G P P_{2000}\end{array}$ & & & & lower $R_{\mathrm{Eco}}$ & upper $R_{E \subset O}$ & \\
\hline $\mathrm{G} \mathrm{C}_{\text {nigh }}$ & 2010-02-09 & - & - & - & - & - & - & - & - & - & - & - & - & - & - & - & - & - & - & - & 1.14 & 0.06 & 1.03 & 1.26 & 6 \\
\hline $\mathrm{G} \mathrm{C}_{\text {ngh }}$ & 2010-03-08 & - & - & - & - & - & - & - & - & - & - & - & - & - & - & - & - & - & - & - & 2.05 & 0.12 & 1.84 & 2.27 & 9 \\
\hline $\mathrm{G} \mathrm{C}_{\text {ngh }}$ & 2010-03-24 & - & - & - & - & - & - & - & - & - & - & -0.03 & -10.99 & 0.01 & 0.63 & -0.05 & -0.01 & -12.29 & -9.69 & 27 & 6.73 & 0.28 & 6.19 & 7.27 & 21 \\
\hline $\mathrm{G} \mathrm{C}_{\text {ngh }}$ & 2010-04-06 & 7.75 & 110.35 & 0.61 & 38.27 & 6.46 & 9.05 & 28.78 & 191.92 & 17 & $T_{\text {air }}$ & -0.02 & -25.30 & 0.00 & 1.27 & -0.02 & -0.01 & -27.94 & -22.65 & 22 & - & - & - & - & - \\
\hline $\mathrm{G} \mathrm{C}_{\text {nigh }}$ & 2010-04-28 & 10.72 & 133.27 & 0.45 & 25.92 & 9.74 & 11.69 & 77.69 & 188.85 & 16 & $S T_{2}$ & -0.02 & -38.83 & 0.00 & 1.90 & -0.03 & -0.01 & -42.86 & -34.80 & 18 & - & - & - & - & - \\
\hline $\mathrm{G} \mathrm{C}_{\text {nigh }}$ & 2010-05-24 & 8.93 & 182.53 & 0.98 & 28.95 & 6.75 & 11.11 & 118.03 & 247.04 & 12 & $T_{\text {air }}$ & -0.05 & -39.66 & 0.00 & 0.98 & -0.06 & -0.04 & -41.73 & -37.60 & 20 & - & - & - & - & - \\
\hline $\mathrm{G}_{\mathrm{n} \text { ngh }}$ & 2010-06-09 & 12.92 & 165.80 & 2.65 & 66.35 & 7.34 & 18.50 & 26.40 & 305.20 & 20 & $S T_{2}$ & -0.09 & -38.11 & 0.01 & 1.15 & -0.12 & -0.06 & -40.49 & -35.74 & 25 & - & - & - & - & - \\
\hline $\mathrm{G}_{\text {nigh }}$ & 2010-07-07 & - & - & - & - & - & - & - & - & - & - & -0.09 & -29.82 & 0.01 & 0.55 & -0.11 & -0.07 & -30.99 & -28.66 & 18 & 16.00 & 0.56 & 14.89 & 17.10 & 15 \\
\hline $\mathrm{G}_{\mathrm{C}} \mathrm{Cgh}$ & 2010-07-21 & 9.76 & 232.70 & 1.90 & 63.17 & 5.47 & 14.06 & 89.79 & 375.61 & 11 & $S T_{2}$ & -0.06 & -30.86 & 0.01 & 0.93 & -0.07 & -0.04 & -32.79 & -28.93 & 25 & - & - & - & - & - \\
\hline $\mathrm{G} \mathrm{C}_{\text {nigh }}$ & $2010-08-22$ & 10.06 & 404.98 & 3.24 & 144.78 & 3.15 & 16.97 & 96.40 & 713.57 & 17 & $S T_{2}$ & -0.09 & -51.92 & 0.01 & 1.60 & -0.12 & -0.07 & -55.24 & -48.59 & 23 & - & - & - & - & - \\
\hline G2C $\mathrm{C}_{\text {igh }}$ & 2010-09-11 & 10.09 & 325.19 & 1.06 & 61.72 & 7.86 & 12.32 & 194.98 & 455.41 & 19 & $S T_{2}$ & -0.10 & -36.65 & 0.01 & 1.01 & -0.13 & -0.07 & -38.72 & -34.57 & 29 & - & - & - & - & - \\
\hline $\mathrm{G} \mathrm{C}_{\text {ngh }}$ & 2010-10-29 & 6.32 & 125.94 & 0.22 & 17.65 & 5.84 & 6.80 & 87.82 & 164.06 & 15 & $T_{\text {air }}$ & -0.03 & -38.30 & 0.00 & 4.25 & -0.03 & -0.02 & -47.49 & -29.11 & 15 & - & - & - & - & - \\
\hline $\mathrm{G} \mathrm{C}_{\text {nigh }}$ & $2010-12-16$ & - & - & - & - & - & - & - & - & - & - & - & - & - & - & - & - & - & - & - & 0.99 & 0.20 & 0.63 & 1.36 & 9 \\
\hline $\mathrm{G}_{\text {(ngh }}$ & 2011-01-05 & - & - & - & - & - & - & - & - & - & - & - & - & - & - & - & - & - & - & - & 2.89 & 0.50 & 1.97 & 3.81 & 9 \\
\hline $\mathrm{G} \mathrm{C}_{\text {nigh }}$ & $2011-01-27$ & - & - & - & - & - & - & - & - & - & - & - & - & - & - & - & - & - & - & - & 5.39 & 0.59 & 4.31 & 6.48 & 9 \\
\hline $\mathrm{G}_{\text {(ngh }}$ & $2011-02-07$ & 2.67 & 111.98 & 0.15 & 31.07 & 2.35 & 2.99 & 46.11 & 177.85 & 18 & $T_{\text {air }}$ & -0.01 & -5.60 & 0.00 & 0.85 & -0.01 & 0.00 & -7.37 & -3.83 & 23 & - & - & - & - & - \\
\hline $\mathrm{G} \mathrm{C}_{\text {nigh }}$ & 2011-03-08 & 2.58 & 67.33 & 0.23 & 25.69 & 2.07 & 3.09 & 11.84 & 122.82 & 15 & $T_{\text {air }}$ & -0.01 & -5.60 & 0.00 & 0.85 & -0.01 & 0.00 & -7.37 & -3.83 & 23 & - & - & - & - & - \\
\hline $\mathrm{G} \mathrm{C}_{\text {nigh }}$ & 2011-03-29 & 9.00 & 162.98 & 0.37 & 24.02 & 8.22 & 9.79 & 111.79 & 214.16 & 17 & $T_{\text {air }}$ & -0.04 & -27.65 & 0.01 & 1.53 & -0.05 & -0.02 & -30.82 & -24.48 & 24 & - & - & - & - & - \\
\hline $\mathrm{G} \mathrm{C}_{\text {nigh }}$ & $2011-04-20$ & 12.16 & 273.72 & 0.54 & 41.96 & 11.00 & 13.33 & 183.07 & 364.37 & 15 & $S T_{2}$ & -0.04 & -40.82 & 0.01 & 1.66 & -0.05 & -0.03 & -44.28 & -37.37 & 23 & - & - & - & - & - \\
\hline $\mathrm{G} \mathrm{C}_{\text {ngh }}$ & $2011-05-10$ & 12.93 & 196.63 & 0.76 & 25.47 & 11.33 & 14.54 & 142.88 & 250.38 & 19 & $S T_{2}$ & -0.08 & -48.03 & 0.01 & 0.95 & -0.09 & -0.06 & -49.98 & -46.08 & 27 & - & - & - & - & - \\
\hline $\mathrm{G}_{\text {(ngh }}$ & $2011-06-21$ & 14.10 & 120.68 & 1.37 & 28.61 & 11.09 & 17.10 & 57.70 & 183.65 & 13 & $T_{\text {air }}$ & -0.09 & -67.43 & 0.01 & 2.65 & -0.12 & -0.07 & -73.07 & -61.79 & 17 & - & - & - & - & - \\
\hline $\mathrm{G}^{\mathrm{C}} \mathrm{C}_{\text {igh }}$ & $2011-06-28$ & 16.82 & 115.08 & 1.18 & 17.50 & 14.36 & 19.28 & 78.69 & 151.47 & 23 & $T_{\text {air }}$ & -0.11 & -52.91 & 0.01 & 0.93 & -0.14 & -0.09 & -54.81 & -51.01 & 31 & - & - & - & - & - \\
\hline $\mathrm{G} \mathrm{C}_{\text {nigh }}$ & $2011-07-26$ & 9.20 & 460.15 & 0.98 & 57.13 & 7.16 & 11.25 & 340.58 & 579.71 & 21 & $S T_{2}$ & -0.10 & -53.96 & 0.01 & 0.86 & -0.12 & -0.09 & -55.72 & -52.21 & 36 & - & - & - & - & - \\
\hline $\mathrm{G} \mathrm{C}_{\text {nigh }}$ & 2011-08-18 & 17.83 & 78.70 & 1.54 & 21.46 & 14.56 & 21.10 & 33.20 & 124.19 & 18 & $T_{\text {air }}$ & -0.10 & -49.63 & 0.01 & 1.08 & -0.12 & -0.07 & -51.85 & -47.41 & 27 & - & - & - & - & - \\
\hline G2C $_{\text {nigh }}$ & $2011-09-16$ & 8.55 & 345.34 & 0.55 & 47.23 & 7.39 & 9.70 & 245.21 & 445.46 & 18 & $S T_{5}$ & -0.01 & -14.66 & 0.00 & 1.41 & -0.02 & -0.01 & -17.59 & -11.74 & 23 & - & - & - & - & - \\
\hline $\mathrm{G} 2 \mathrm{C}_{\text {ngh }}$ & $2011-10-16$ & 7.96 & 145.79 & 0.29 & 38.84 & 7.33 & 8.59 & 61.16 & 230.42 & 14 & $S T_{2}$ & -0.03 & -33.96 & 0.00 & 1.67 & -0.04 & -0.03 & -37.49 & -30.43 & 19 & - & - & - & - & - \\
\hline $\mathrm{G} \mathrm{C}_{\text {nigh }}$ & $2011-12-15$ & - & - & - & - & - & - & - & - & - & - & -0.06 & -20.27 & 0.01 & 3.78 & -0.07 & -0.04 & -29.20 & -11.35 & 9 & 3.40 & 0.15 & 3.12 & 3.68 & 9 \\
\hline $\mathrm{G}_{2} \mathrm{C}_{\text {ing }}$ & $2012-01-12$ & 7.19 & 248.93 & 1.31 & 76.03 & 4.30 & 10.08 & 81.58 & 416.28 & 13 & $T_{\text {air }}$ & -0.03 & -18.45 & 0.00 & 1.58 & -0.04 & -0.02 & -21.89 & -15.00 & 14 & - & - & - & - & - \\
\hline
\end{tabular}

